\title{
Beyond Home Bias: Portfolio Holdings and Information Heterogeneity
}

\author{
Filippo De Marco* $\quad$ Marco Macchiavelli ${ }^{\dagger} \quad$ Rosen Valchev ${ }^{\ddagger}$
}

January 28, 2019

\begin{abstract}
We study whether information frictions are important determinants of banks' international portfolio holdings. Going beyond the classic distinction of home versus foreign assets, we focus on the heterogeneity within foreign holdings. First, we document that banks invest only in a few foreign countries, even when considering a class of assets that is highly homogeneous across destination countries (European sovereign bonds). Large, global banks have portfolios that are more diversified than small banks but they still overweight domestic assets relative to foreign. Second, we propose a new model with a two-tiered information cost structure - including both a fixed and a variable component - that can rationalize these facts. Finally, we test the key predictions of the model in the data. We find that more precise information leads to larger holdings, and also amplifies the effect of expected returns on portfolio holdings.
\end{abstract}

JEL classification: F30, G11.

Keywords: Home bias, Information frictions, Portfolio choice, Banks

We are grateful to Philippe Bacchetta, Andrea Beltratti, Stephen Cecchetti, Nicolas Coeurdacier, Kimberly Cornaggia, Nicola Gennaioli, Tarek Hassan, Sebnem Kalemli-Ozcan, Nicola Limodio, Matteo Maggiori, Thomas Maurer, Alvaro Pedraza, Felipe Saffie, David Thesmar, Andrea Vedolin, Laura Veldkamp, Francis Warnock and conference participants at AFFI 2017, EFA 2018, MFA 2018, NBER SI (IFM) 2018, Minnesota Finance Juniors Conference 2018 for helpful comments. Jamie Grasing provided excellent research assistance. The views expressed in this paper are those of the authors and do not necessarily reflect those of the Board of Governors or the Federal Reserve System.

*Bocconi University, Baffi-Carefin and IGIER, Via Roentgen 1, 20136 Milan, Italy. Phone:+39-02-58365973, email: filippo.demarco@unibocconi.it

${ }^{\dagger}$ Federal Reserve Board, 20th and C Street NW, Washington, DC 20551. Phone: +1 202-815-6399, email: marco.macchiavelli@frb.gov

${ }^{\ddagger}$ Boston College, Maloney Hall 396, Chestnut Hill, MA 02467. Phone: +1 617-552-8704, e-mail: valchev@bc.edu 


\section{Introduction}

Portfolio home bias, the surprising lack of international diversification in portfolios, is a well documented empirical phenomenon in international finance, that has given rise to a large and active literature. ${ }^{1}$ One of the leading explanations, costly information acquisition, is appealing in that it fits a number of features of the home bias in the data (see for example Van Nieuwerburgh and Veldkamp (2009), Dziuda and Mondria (2012), Valchev (2017)). Largely due to the lack of appropriately disaggregated data, however, the primary focus of prior work has been on understanding the basic dichotomy between home and foreign assets, while the heterogeneity among individual foreign holdings has received less attention.

In this paper, we go beyond the classic home versus foreign distinction in holdings, and study both theoretically and empirically how information frictions affect the sovereign debt portfolio of European banks between 2010 and 2013, with a specific focus on the allocation across individual foreign holdings. ${ }^{2}$ Our unique dataset allows us to analyze not only the portfolio allocation between home assets and specific foreign assets, but also to link portfolio holdings to beliefs about the expected returns on the individual assets over the same period. Moreover, we have a time series of individual expected returns for each bank-asset pair, hence we are able to evaluate the objective precision of different beliefs, and provide direct evidence in support of rational information-based models of international portfolio allocation. Our work suggests that differences in expectations and information quality are significant determinants of portfolio concentration, even among sophisticated investors, such as the

\footnotetext{
${ }^{1}$ For the empirical documentation of the puzzle see, among others, French and Poterba (1991), Tesar and Werner (1998), and Ahearne et al. (2004). In terms of theories of the home bias see, for example, Obstfeld and Rogoff (2001), Van Nieuwerburgh and Veldkamp (2009), Coeurdacier and Gourinchas (2016), Heathcote and Perri (2013), Huberman (2001). Coeurdacier and Rey (2013) provide an excellent survey.

${ }^{2}$ Our model covers only tradable assets and since the data on sovereign bond holdings give the best coverage of banks over time, we focus on that specific asset class in the empirical analysis. However, we show that international holdings of bank sovereign debt are highly correlated with both equity and credit exposures for the dates in which data are available. Moreover, focusing on sovereign debt allows us to abstract from the currency of denomination of debt (Maggiori et al. (2018)). In fact, $98 \%$ of sovereign debt issued by EEA countries is denominated in the domestic currency (mostly in euros), hence the home bias due to the nationality of the issuer or the currency of denomination are not distinguishable in our data.
} 
largest European banks in our sample. ${ }^{3}$

We begin by discussing the stylized facts that characterize foreign portfolio holdings in our data set. We find that the foreign portion of a bank portfolio is typically 'sparse', in the sense that banks tend to hold sovereign debt from only a small subset of foreign countries (even when we restrict those countries to be from the relatively homogeneous set of European Union countries). We call this fact the extensive margin of the home bias. For the average bank, $60 \%$ of the observed home bias is due to the extensive margin. Specifically, when we compute a counterfactual index of home bias where the "zeros" in the portfolio are replaced with the optimal market shares, the average home bias decreases by $60 \%$. There is, however, substantial cross-sectional heterogeneity in the incidence of the extensive margin. The home bias of small banks, which is higher on average than for large banks, is almost entirely due to the extensive margin. The home bias of the largest banks instead is due to the fact that, although they invest in a large number of foreign countries, they still significantly underweight foreign countries as a group relative to domestic holdings. This is the intensive margin of the home bias. The distinction between extensive and intensive margin of international portfolio choice is an interesting pattern that has not received much prior attention. ${ }^{4}$

Next, we propose a general equilibrium model with costly information acquisition that is able to rationalize these stylized facts. The modeling challenge is to generate both the extensive margin (invest in a limited set of foreign countries) and the intensive margin (underweight any foreign investments you do make) of portfolio adjustment, and the proper cross-sectional heterogeneity in the importance of both for small and large banks. To do that,

\footnotetext{
${ }^{3}$ Our results speak to the existence of objective differences in information quality among sophisticated investors, and to the fact that those investors are aware and act upon their specific information advantages. In contrast, among retail investors, prior research has shown that portfolio concentration is linked to behavior mistakes stemming from the lack of sophistication, see Campbell et al. (2007), Goetzmann and Kumar (2008), Guiso and Jappelli (2008), Kimball and Shumway (2010), Gaudecker (2015).

${ }^{4}$ Using security-level data of all US investors holdings of foreign firms, Ammer et al. (2012) and Lenz et al. (2009) document that about $25 \%$ of foreign firms receive no US investment at all. They show that the decision not to cross-list in the US and poor corporate governance can explain this pattern. Hau and Rey (2008) and Shin (2014) similarly notice that mutual funds tend to specialize in specific geographical regions, and often avoid investing in other regions altogether. They also show that larger funds tend to invest in a broader set of foreign countries, as large banks do in our sample. However, they do not analyze whether the sparseness persists within sets of homogeneous destination countries.
} 
we modify the benchmark model of Van Nieuwerburgh and Veldkamp (2009), which features an intensive margin of information and portfolio adjustment, but not an extensive one, in two ways. First, we make the information choice and cost structure two-tiered by including Merton (1987)-style fixed cost of acquiring initial information about the unconditional distribution of returns. We view such fixed costs as the substantial cost in due diligence and compliance that the bank risk management requires before a new asset is added to the portfolio (Saunders and Cornett (2013)). ${ }^{5}$ Second, we use CRRA preferences (as opposed to CARA) which introduce a wealth effect and thus decreasing marginal utility of paying for additional information. Thanks to these two new elements (both of which are needed), the optimal portfolios are sparse, with less wealthy agents (e.g. smaller banks) optimally choosing to pay the fixed cost to acquire information about (and thus invest in) fewer foreign countries. Thus, the model features both extensive and intensive margins of portfolio adjustment, and an explicit role for bank size. ${ }^{6}$

In the model, agents can receive two types of information: (i) information on the unconditional distribution of returns and (ii) noisy signals, with endogenous precision, on the future return realizations of individual assets. The second type of information (which we call intensive information) works in the same way as in Van Nieuwerburgh and Veldkamp (2009), and similarly displays increasing returns and thus the optimal choice of intensive information is to acquire informative signals about only one country (which turns out to be the home country). The first type of information (which we call extensive information) is new to our paper, and it turns out that it does not display increasing returns, but rather decreasing returns. This is due to the interaction between CRRA utility and the optimal allocation of intensive information. On the one hand, agents know that they will optimally choose to not acquire additional informative signals for the foreign countries they invest in,

\footnotetext{
${ }^{5}$ For example, the Federal Reserve guideline for bank examiners (found here) states that "In general, a bank should not trade a product until senior management and all relevant personnel (including those in risk management, internal control, legal, accounting, and audit) understand the product and are able to integrate the product into the financial institution's risk-measurement and control systems".

${ }^{6}$ Gârleanu et al. (2016) develop a model with a discrete type of information friction which can also generate non-participation, but do not study its potential implications about international portfolio sparseness.
} 
which weakens the feedback loop between extensive information and portfolio holdings. On the other, the CRRA agents face decreasing marginal utility of investable wealth, and thus increasing marginal cost of information in utility terms. As a result, agents might optimally choose to save on the fixed information cost for some countries and only invest in a strict subset of all available countries. Thus, the model displays both increasing returns to intensive information, and decreasing returns to extensive information.

Lastly, the dual structure of information implies that there are two channels through which portfolios become home-biased in equilibrium: (i) agents may acquire priors on a subset of foreign countries (thus leading to sparse portfolios) and (ii) agents only acquire additional informative signals about the domestic asset, which increases its portfolio weight relative to the set of foreign assets the bank is actually investing in. Moreover, the model also has rich implications about the composition of the foreign portion of agents' portfolios, which depends on the optimal acquisition of foreign information. With the model's predictions at hand, we use our dataset that links bank forecasts and bank sovereign portfolio holdings to document the importance of information frictions in determining both the extensive margin, and the intensive margin of international portfolio allocations.

First, we show that indeed banks have an informational advantage over their home country, in the sense of producing more accurate forecasts on their domestic country relative to foreign ones. ${ }^{7}$ This justifies the basic economic intuition of our model that portfolio bias is due to information differences across potential investments. Second, we show that producing a forecast about a country strongly predicts the likelihood of investing in that country. In other words, information acquisition seems to determine portfolio sparseness, just as it does in the model. These facts support the link between information frictions and the extensive margin of portfolio choice. ${ }^{8}$

\footnotetext{
${ }^{7}$ Similar local information advantages are also documented in other settings by prior work. For instance, Bae et al. (2008) and Malloy (2005) study how geographical and cultural proximity affects accuracy for analysts, while Grinblatt and Keloharju (2001) find similar patterns for Finnish stock investors. Cornaggia et al. (2017) confirm that proximity leads credit rating analysts to issue more favorable ratings.

${ }^{8}$ In international trade, the connection between information frictions and the extensive margin of trade (which export market to enter) is studied in Morales et al. (2017) and Dickstein and Morales (2015).
} 
We then turn our attention to the link between the intensive margin of information and the intensive margin of portfolio bias. We show that, conditional on producing forecasts on a set of countries, the precision and relative optimism of these forecasts have statistically and economically significant effects on a bank's holdings in these countries. Specifically, both more optimistic expectations about a country and more precise information (lower squared forecast errors) strongly predict larger portfolio holdings of that country's sovereign debt. In addition, and as implied by the model, there is a significant interaction effect between the precision and the relative optimism of the forecasts: a given change in the bank's forecast produces a larger shift in the holdings of that country's sovereign debt, the more precise the forecast is. In other words, precise information amplifies the effect of forecasts on portfolio allocations. $^{9}$

Lastly, we find that while information differences can explain the heterogeneity in the foreign portion of the sovereign portfolio, they cannot fully account for the significant overweighting of domestic assets relative to foreign assets as a whole. Indeed, when we run the intensive margin regressions including home exposure dummies, the latter show positive and significant coefficients. The home exposure dummies have explanatory power over and above what can be attributed to any home advantage in information. Thus, we conclude that information frictions play an important role in determining the heterogeneity in banks' foreign portfolio holdings, but they are not quite enough by themselves to explain the full extent of the classic home bias puzzle.

This paper contributes to the large literature on home bias in asset holdings. The basic observation has been extensively documented for both equities (French and Poterba (1991), Tesar and Werner (1998), Ahearne et al. (2004)) and bonds (Burger and Warnock (2003), Fidora et al. (2007), Coeurdacier and Rey (2013)), and is a robust feature of both the aggregate data and the micro, individual investor data (Huberman (2001), Ivković and

\footnotetext{
${ }^{9}$ In robustness tests (Tables 13 and 14 in Appendix D), we rule out that our results are driven by reverse causality, since past forecast precision is useful to predict future holdings, or by the sovereign debt crisis of 2011-2012, since we control for destination country-time fixed effects and exclude exposures to the peripheral countries at the core of the crisis.
} 
Weisbenner (2005), Massa and Simonov (2006), Goetzmann and Kumar (2008)). Recently, the European debt crisis has specifically emphasized the role of home bias in European banks' sovereign portfolios in transmitting credit risk from sovereign to the real economy (Popov and Van Horen (2014), Altavilla et al. (2017), DeMarco (2017)).

In terms of potential theoretical explanations, the idea of information frictions that create information asymmetry between home and foreign agents is a well-established hypothesis with a long tradition in the literature (Merton (1987), Brennan and Cao (1997), Hatchondo (2008), Van Nieuwerburgh and Veldkamp (2009), Mondria (2010), Valchev (2017)). Another set of mechanisms study frameworks in which home assets are good hedges for real exchange rate risk (Adler and Dumas (1983), Stockman and Dellas (1989), Obstfeld and Rogoff (2001), Serrat (2001)) and/or non-tradable income risk (Heathcote and Perri (2013), Coeurdacier and Gourinchas (2016)). Yet another strand of the literature analyzes corporate governance issues (Dahlquist et al. (2003)), political economy mechanisms (DeMarco and Macchiavelli (2015), Ongena et al. (2016)) and behavioral biases (Huberman (2001), Portes and Rey (2005), Solnik (2008)). Maggiori et al. (2018) argue instead that in the context of the corporate bond market, it is the currency of denomination of debt, rather than the nationality of the issuer, that determines the portfolio allocations of foreign investors.

The contribution of this paper in terms of the home bias literature is twofold, both theoretical and empirical. On the empirical side, we provide new stylized facts about banks' international portfolio holdings, and in particularly show that there is an important extensive margin to international under-diversification. Crucially, we also empirically link both the extensive and intensive margin of portfolio adjustment to information frictions. To the best of our knowledge, we are the first to directly link investors' information sets with their portfolio holdings empirically. Previous empirical studies on information frictions, even those at the investor level, cannot match each asset in the investor's portfolio with his or her expectation (and its accuracy) about the performance of the asset. By connecting information sets with asset allocations at the bank level, we are able to provide direct evidence in favor of the main 
implications of portfolio choice models with information frictions.

On the theoretical side, we extend the standard portfolio choice model with costly information (Van Nieuwerburgh and Veldkamp (2009)) by adding an extensive margin of information acquisition and power utility preferences that generate wealth effects. In this model, home bias is driven by both an intensive and an extensive margin, and generates portfolios that can rationalize the stylized facts we document. The model also has rich implications about the structure of the foreign portion of portfolios, that fits well with the new evidence we provide on the link between the extensive margin of information acquisition and the extensive margin (sparseness) of portfolio holdings. Moreover, its more detailed implications are also well supported by our empirical tests.

The paper is organized as follows. Section 2 describes the data and presents stylized facts. Section 3 presents the model and Section 4 empirically tests the implications from the model. Finally, Section 5 concludes.

\section{Data and Stylized Facts}

\section{$2.1 \quad$ Data}

For our purposes, it is key to have data on holdings and expected returns of sovereign debt at the individual asset-investor level. To this end, we merge information on European banks' sovereign portfolios from the European Banking Authority (EBA) to banks' forecasts from Consensus Economics.

The EBA data, collected for the bank stress tests, is a semi-annual dataset of sovereign exposures of the largest banks headquartered in the European Economic Area (EEA) from 2010Q1 to 2013Q4. ${ }^{10}$ In order to keep our assets under study relatively homogeneous, we focus on the exposures to EEA sovereigns, excluding countries such as Japan, USA and

\footnotetext{
${ }^{10}$ The stress tests were held at irregular intervals, thus the following reporting dates are available: 2010Q1, 2010Q4, 2011Q3, 2011Q4, 2012Q2, 2012Q4, 2013Q2 and 2013Q4.
} 
Switzerland. ${ }^{11}$ We do so for several reasons. First of all, because of data limitations: exposures to non-EEA countries are only available in 2010Q4 and 2013Q4, not in other dates. Second, restricting the sample to EEA countries yields a homogeneous group in terms of regulatory treatment: in fact, all exposures to EEA central governments denominated in local currency (98\% of total debt outstanding) are assigned a 0\% risk-weight (ESRB (2015)). The different regulatory treatment or liquidity characteristics may explain why European banks hold so little non-EEA debt, but cannot directly account for the home bias among EEA countries. Finally, sovereign bonds are a highly relevant asset class for European banks, as they form a significant proportion of their total security portfolios. Over the period 2010-2013, EBA banks hold a total of $€ 2$ trillion in sovereign debt from EEA countries (out of about $€ 12$ trillion in total outstanding public debt), €146 billion in equity holdings and $€ 10$ trillion in credit exposures to non-financial firms (out of about $€ 15$ trillion in total European banks lending to non-financial corporates).

We match the banks in the EBA sample to Consensus Economics, a survey of professional forecasters which includes many of the banks in our sample as participants. At the beginning of each month, Consensus surveys analysts working for banks, consulting firms, non-financial corporations, rating agencies, universities and other research institutions (see Table 10 in the Appendix D for a detailed list of forecasters). These analysts provide forecasts for a set of key macroeconomic and financial variables for all major industrialized countries and some emerging ones. The forecasters include both domestic and foreign institutions. We match by name the banks in Consensus Economics to those in the EBA dataset. In case banks appear through their international subsidiaries, we match the subsidiary's forecast to the portfolio of the banking group it belongs to-HSBC France forecasts for the French economy is matched with the share of French bonds in the consolidated portfolio of HSBC Holdings, a British bank.

In the empirical analysis we use the 10-year sovereign yields as the forecasting variable,

\footnotetext{
${ }^{11}$ The stylized facts are not affected if we include exposures towards non-EEA countries in the sample (if anything, they are even stronger).
} 
because it is the most relevant forecast in the Consensus database in terms of determining expected returns on sovereign debt. Expecting a higher future yield on a debt instrument (which provides a fixed stream of payments) translates into expecting a lower future price, and thus a lower current return.

Since we have a time series of forecasts for bank-country pairs, our data allows us to construct an objective measure of the precisions of the banks' forecasts. We construct the precision of bank b's forecast for country $c$ at forecasting horizon $h$ as the resulting average squared forecast error (SFE): $S F E_{b c t}^{h}=\left(E_{b t}\left(X_{c, t+h}\right)-X_{c, t+h}\right)^{2}$, where $X_{c, t+h}$ is the realization of 10-year yields of country $c$ at time $t+h$ and $E_{b t}\left(X_{c, t+h}\right)$ represents the forecast as of time $t$ of 10 -year yields $h$ periods ahead. Since the SFE may be a noisy measure of the average forecast precision of a given bank for a given country, our preferred measure of information precision is the average squared forecast error for the whole sample period, i.e. $\overline{S F E}_{b c}^{h}=\frac{1}{T} \sum_{t=1}^{T}\left(E_{b t}\left(X_{c, t+h}\right)-X_{c, t+h}\right)^{2}$. There are two forecast horizons reported by Consensus: short-term (3-months ahead) and long-term (1-year ahead). For our benchmark results, we focus on the short horizon (3-months ahead) forecasts that are likely to have a more immediate effect on portfolios, but we also conduct and report robustness checks using the 1-year ahead forecast; we therefore omit the $h$ superscript hereafter.

Table 2 contains the list of variables that we use in the empirical analysis. The forecasts on 10-year yields are available for 85 banks at the monthly frequency from September 2006 to December 2014 for 14 different EEA countries. ${ }^{12}$ We are able to match 40 of the forecasters to the sample of EBA banks, from which we obtain information on sovereign bond holdings for all 14 destination countries. Table 3 displays summary statistics for the dataset. In Panel A we report summary statistics of 10-year yield forecasts from all bank-forecasters available on Consensus Economics. The average point forecast for 10-year yields is $3.37 \%$ for all 14 countries between 2006 to 2014. The average squared forecast error is 0.35 , which is roughly only one-fourth of the standard deviation of the 10-year yields, suggesting that banks indeed

\footnotetext{
${ }^{12}$ See Tables 9 in Appendix D for a list of countries.
} 
have a significant ability to forecast future yields. The time-averaged squared forecast error per forecaster is a bit higher on average (0.44), with a standard deviation of 0.54 which shows that there is significant heterogeneity in the ability of different banks to forecast different yields. In our main empirical results we will aim to leverage this heterogeneity to see if it can help explain the heterogeneity in portfolio holdings.

In Table 3, we also report the summary statistics for the sovereign debt portfolio holdings of our matched EBA-Consensus sample. One striking observation (that we elaborate upon below) is that most banks invest in just a few of the potential foreign countries, hence there are a lot of zeros in the portfolios: about $40 \%$ of the bank-country pairs observations show no exposure at all $\left(\mathbf{1}\left(\right.\right.$ ShareSovEE $\left.\left.A_{b, c, t}\right)=0\right)$. To highlight this, in Panel B we present summary statistics for the overall portfolios (i.e. including all bank-country pairs), and in Panel $\mathrm{C}$ we present summary statistics of the non-zero portfolio holdings of banks (i.e. excluding bank-country pairs where the bank has no holdings of that country's sovereign debt). The shares of sovereign debt are markedly different across panels. In Panel B, we see that the average sovereign portfolio share, including the domestic exposure, is about $4.53 \%$, with a large standard deviation (14.32\%). If we exclude the holdings of domestic sovereign debt, both the average share of each investment and its standard deviation are halved compared to before (2\% and $6 \%)$, highlighting the large domestic exposures most banks have. In Panel $\mathrm{C}$, where we restrict the sample to bank-country pairs with positive exposure, the average portfolio holding increases to $20 \%$ ( $12 \%$ across foreign positive exposures only). Point forecasts and squared forecast errors of 10-year yields remain similar to the full sample.

\subsection{Stylized Portfolio Facts}

In our first set of empirical results, we exploit the heterogeneity in our dataset, both across banks and across foreign assets, to better understand the structure of the home bias in sovereign debt holdings. To quantify this bias, we use the standard measure in the literature, 
the Home Bias Index (HB Index):

$$
\mathrm{HB}=1-\frac{1-x_{H}}{1-x_{H}^{*}}
$$

where $x_{H}$ is the portfolio share of a bank's holdings of domestic sovereign debt and $x_{H}^{*}$ is the share of home country's debt as a fraction of total world debt (the CAPM portfolio). The HB index takes the value of zero when the investor holds domestic assets in the same proportion as the benchmark CAPM portfolio $\left(x_{H}=x_{H}^{*}\right)$, is positive when domestic assets are over-weighted, with a limiting value of 1 when the whole portfolio is composed exclusively of domestic assets $\left(x_{H}=1\right)$. It can be negative if domestic assets are under-weighted compared to the CAPM portfolio $\left(x_{H}<x_{H}^{*}\right)$. This index is the benchmark measure of portfolio under-diversification because it sidesteps the potentially thorny issue of computing expected returns and variances, and provides a simple statistic to compare models against.

Figure 1: Home Bias Index Histogram

This figure plots the distribution for the home bias index, $\mathrm{HB}=1-\left(1-x_{H}\right) /\left(1-x_{H}^{*}\right)$, for all EBA banks in 2010Q1-2013Q4.

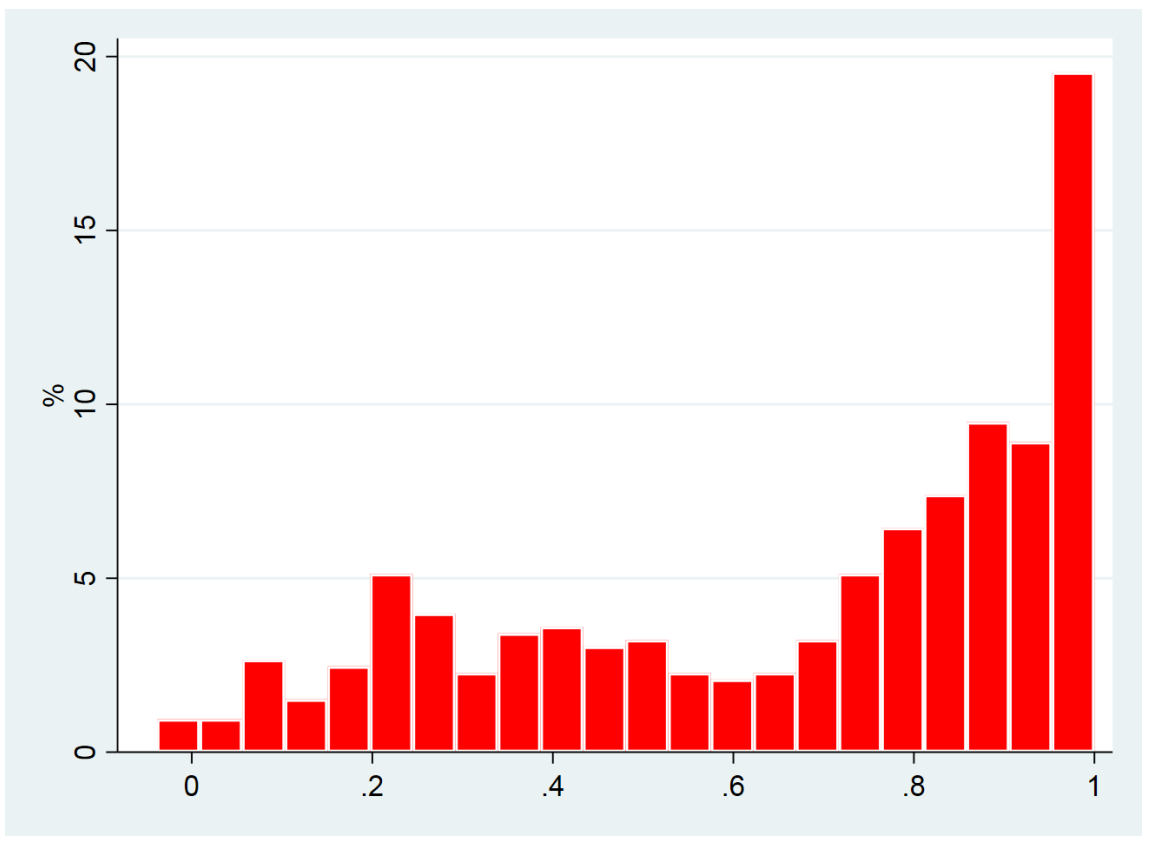

The histogram of HB values for the different banks in our dataset pooling across all 
dates (2010Q1-2013Q4) is presented in Figure 1. Virtually all banks display at least some home bias (except for BNP Paribas, that has a negative HB index) and the median (mean) at $0.72(0.61)$ is quite high. This value implies that the foreign holdings of the median (average) bank are only $28 \%(39 \%)$ as big as they would have been under the CAPM benchmark allocation. Hence, we observe that home assets are significantly overweighted as compared to foreign assets-this is the basic observation of the home bias that has also been documented extensively in many previous studies. Size is a big driver of the overall level of home bias, but cannot alone explain it. In Figure 2 we sort banks according to the quintiles of total assets in 2010: while many of the banks in the bottom quintile of assets $(<€ 38$ billion in assets) hold almost exclusively domestic debt, even the largest international banks (>€550 billion in assets) show significant home bias.

Figure 2: Home Bias Index: Small vs. Large Banks

This figure plots the distribution for the home bias index, $\mathrm{HB}=1-\left(1-x_{H}\right) /\left(1-x_{H}^{*}\right)$, by bank size. Panel (a) plots the distribution for banks in the bottom quintile of total assets in 2010 ( $<€ 38$ billion), while Panel (b) for banks in the top quintile of total assets in 2010 (>€550 billion).

(a) Small

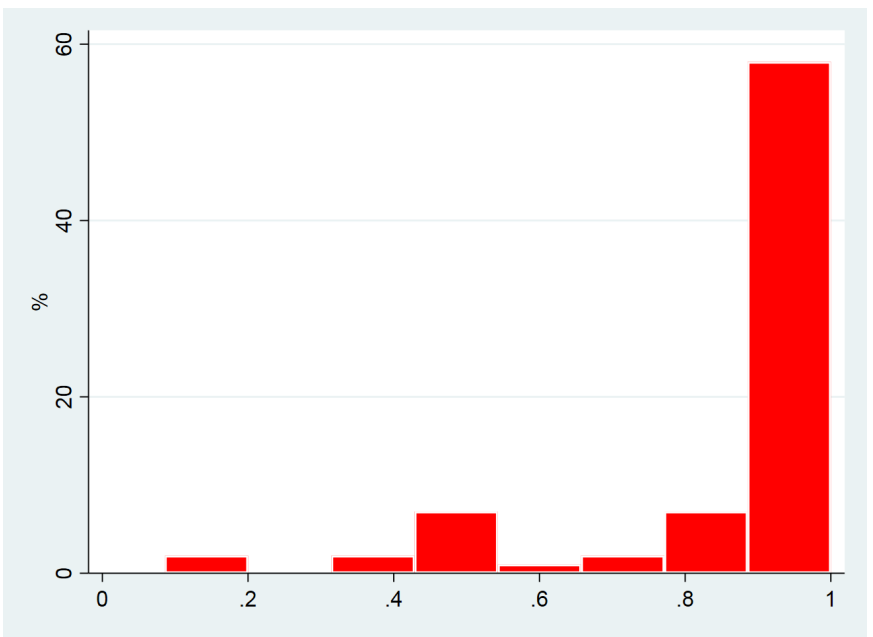

(b) Large

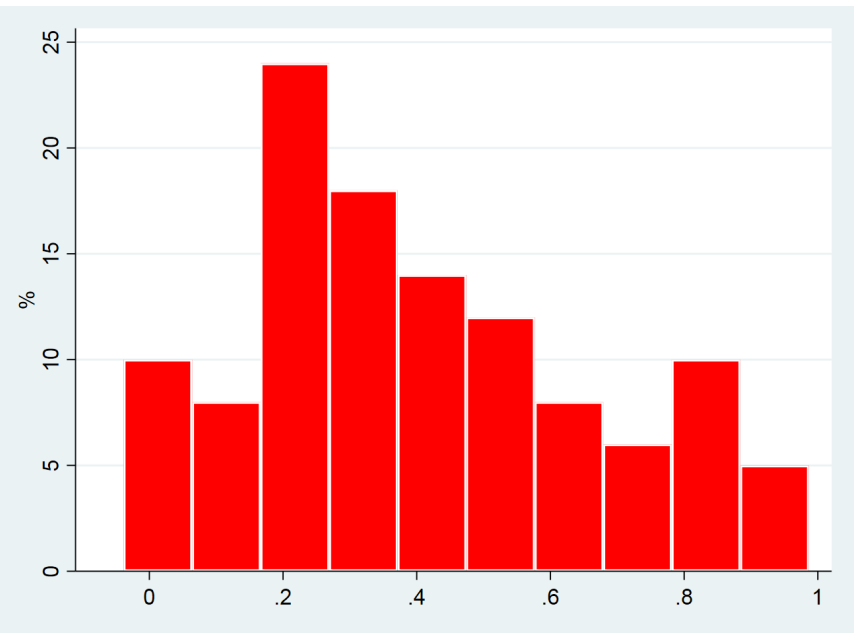

For the next set of results, it is useful to rewrite the HB index as:

$$
\text { Home Bias }=1-\frac{\sum_{j \neq H} x_{j}}{\sum_{j \neq H} x_{j}^{*}}
$$


where $x_{j}$ is the share of foreign country $j$ bonds in the bank's portfolio, and $x_{j}^{*}$ is the share of country $j$ bonds in total world debt. That is, rather than subtracting the domestic exposure from one, we sum over all foreign holdings $\left(1-x_{H}=\sum_{j \neq H} x_{j}\right)$. This equivalent expression is useful for the counterfactual measures of home bias considered below.

Extensive Margin of Home Bias: Another prominent feature of the data is that portfolios are sparse: the average bank between 2010 and 2013 only invests in 11 out of the 27 potential foreign EU countries (and only 8 out 19 euro-area countries).

Figure 3: Home Bias Index: Adjusting the Extensive Margin, Small and Large Banks

This figure plots the distribution for a counterfactual home bias index replacing all zero exposures with the optimal portfolio shares $\left(x_{j}=x_{j}^{*}\right.$ if $\left.x_{j}=0\right)$. Panel (a) plots the distribution for banks in the bottom quintile of total assets in 2010 (<€38 billion), while Panel (b) for banks in the top quintile of total assets in 2010 (>€550 billion).

(a) Small

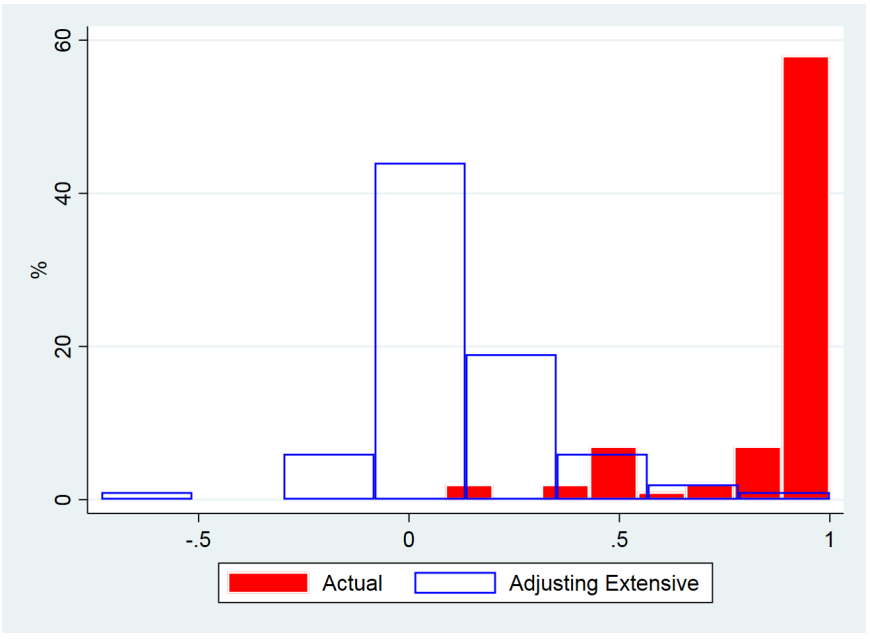

(b) Large

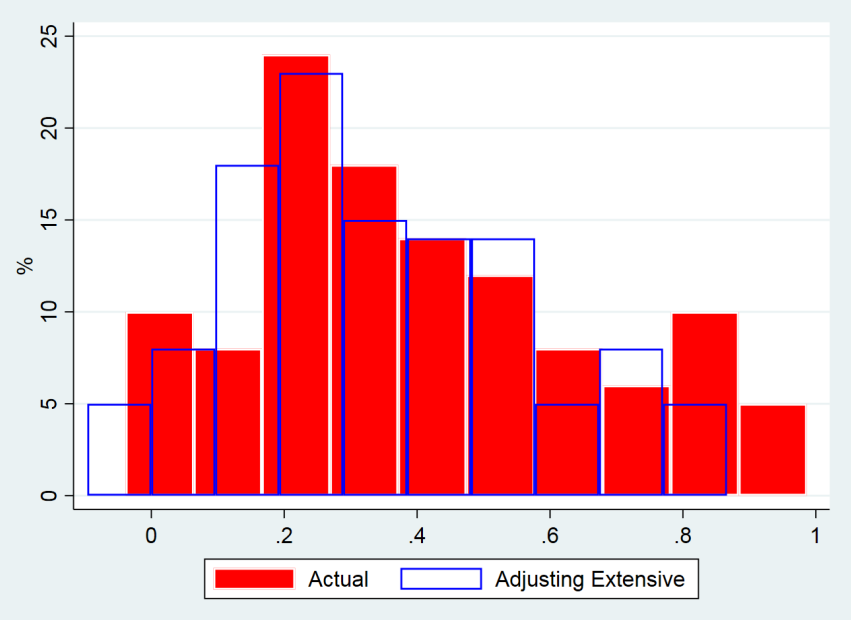

To quantify the extensive margin of the home bias, we construct a counterfactual home bias index for each bank by setting the portfolio share of foreign sovereigns held in zero quantities equal to their world market share, i.e. we set $x_{j}=x_{j}^{*}$ for all $x_{j}=0, j \neq H$. Thus, the actual portfolio deviates from the counterfactual portfolio only through its zeroes, i.e. its sparseness. The results are presented in Table 1. The average home bias index is reduced from 0.61 to 0.25 by adjusting the extensive margin, a decrease of about $60 \%$. The result for 
the average bank hides a considerable heterogeneity depending on the size of the bank. We show the heterogeneity by bank size in Figure 3 where we adjust the extensive margin for small and large banks separately, in panels (a) and (b).

We see that the extensive margin is indeed a major driver of the home bias for small banks: correcting it leads to a strong shift of the HB distribution towards zero, with a median (average) home bias of just 0.06 (0.09). Thus, the main driver of the home bias for small banks is the fact that those institutions do not invest at all in many foreign countries. On the other hand, eliminating the extensive margin has a small effect on the home bias distribution for the largest banks. Those institutions tend to invest in the sovereign debt of all EU countries already, and only a small portion of their overall home bias can be attributed to portfolio sparseness.

Figure 4: Home Bias Index: Adjusting the Intensive Margin, Small and Large Banks

This figure plots the distribution for a counterfactual home bias index replacing all non-zero exposures with the optimal portfolio shares $\left(x_{j}=x_{j}^{*}\right.$ if $\left.x_{j}>0\right)$. Panel (a) plots the distribution for banks in the bottom quintile of total assets in 2010 ( $<€ 38$ billion), while Panel (b) for banks in the top quintile of total assets in 2010 (>€550 billion).

(a) Small

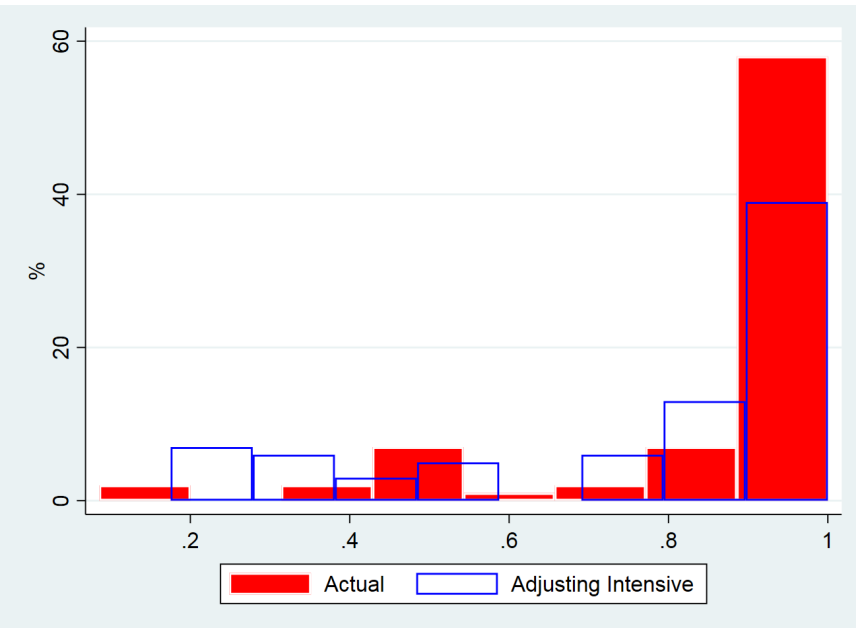

(b) Large

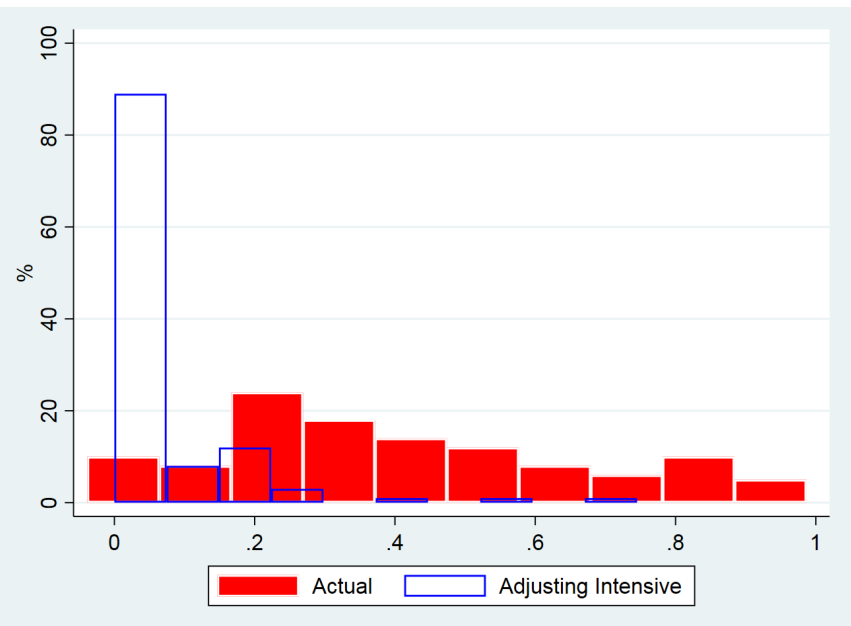

Intensive Margin of Home Bias: The other way in which the home bias might arise (even if a bank invests some amount in all foreign countries) is through the intensive margin 
of portfolio adjustment, over-weighting domestic relative to foreign holdings. To measure the extent of this intensive margin of home bias in our data, we construct a different counterfactual home bias index, where we set the portfolio share of all non-zero foreign investments equal to their respective market share, while leaving the zeros unchanged $\left(x_{j}=x_{j}^{*}\right.$ if $\left.x_{j}>0\right)$. We report the results for all banks in Table 1 and we plot the results for small and large banks separately in panel (a) and (b) of Figure 4.

It is striking to see how in this case the home bias for large banks is almost entirely eliminated, while it is still significant for small banks. This is the flip side of the adjustment on the extensive margin we saw previously. Taking both results together, we can conclude that while small banks still underweight the foreign investment they hold in positive quantities, most of their home bias is explained by the fact that they do not invest at all in many countries. Large banks, on the other hand, tend to invest in all countries, but significantly underweight their foreign investments compared to holdings of domestic assets. To sum up, the extensive margin is the main driver of small banks' home bias, while for large banks it is the intensive margin.

Implied Variance Reduction: We have focused our attention on a relatively homogeneous asset class in order to minimize potential frictions that could mechanically explain the apparent lack of diversification. It is certainly possible, however, that such homogeneous assets are highly positively correlated, and hence the diversification benefits in terms of lower portfolio variance might be small. In particular, could it be that banks hold sparse portfolios because the countries they do not invest in actually offer very little in terms of practical diversification opportunity?

It turns out that this is not the case, for two reasons. First, the median (mean) correlation of quarterly 10-year EU bond returns (our benchmark maturity) in our sample over 2005-2013 is only $0.5(0.52) .{ }^{13}$ This is far from a perfect correlation. Second, the banks

\footnotetext{
${ }^{13}$ For robustness considerations we chose to use a large sample than the 2010-2013 period of portfolio observations. The 2005-2013 sample matches our forecasting data set, and is the time period over which we
} 
that display a lot of sparseness in their portfolios not only forgo investment in countries that tend to comove with each other (i.e. France and Italy), but often also investment in hedge countries such as Germany and Denmark.

To quantify the implied diversification loss in terms of increased volatility, we compute the difference between the variance of empirically observed portfolios and the minimum variance portfolio. To compute variances, we use the unconditional variance-covariance matrix of EU bond returns over the period 2005-2013. We find that the empirical portfolios have significantly higher implied variances than the minimum variance portfolio, suggesting that there are potential gains from diversification even within our homogeneous class of assets. The median (average) bank portfolios exhibits a variance that is 64\% (118\%) larger than that of the minimum variance portfolio.

Furthermore, roughly half of this implied excess variance is due to the sparseness in bank portfolios-hence banks do forgo investment in countries that could offer significant diversification benefits. To quantify this effect, for each bank-quarter observation we compute counterfactual portfolios where we correct any zero holdings to equal their corresponding weight in the minimum variance portfolio. We find that, after correcting the zeros in this way, the median (average) portfolio would have had a variance that is only $36 \%$ (44\%) above the minimum variance portfolio. On the other hand, correcting the intensive margin of portfolios (by replacing any non-zero weights with corresponding minimum variance portfolio weights) implies that the median (average) bank portfolio would have had a variance that is $47 \%$ (85\%) higher than the minimum variance portfolio. Hence, the observed portfolio sparseness plays a larger role in explaining the excess volatility of observed portfolios.

Figure 5 plots the distribution of the excess standard deviation of the empirical portfolios over the minimum variance portfolio (i.e. $\ln \left(\sqrt{\left.\frac{\operatorname{Var}_{b t}}{\operatorname{Var}_{\text {min }}}\right)}\right)$ in blue. As we can see, there are some large positive outliers (which drive the big difference between mean and median reported above), but more importantly more than three quarters of the distribution has an excess

evaluate the banks' ability to forecast yields. Nevertheless, the basic facts of this section are also true in the shorter, 2010-2013 sample. 
standard deviation of over 20\% (hence excess variance of over 44\%). Correcting for the extensive margin of portfolio under-diversification (in red) helps reduce the implied excess volatility substantially: it produces a marked left shift in the distribution of excess volatility and bunches it close to zero. Moreover, it eliminates almost all of the large positive outliers. Overall, we conclude that the sparseness of portfolios is not driven by lack of practical diversification benefit of the forgone investments.

Figure 5: Variance increase compared to minimum variance portfolio

This figure plots the distribution of the excess variance of bank portfolios (over minimum variance portfolio) in blue in both panels. In left panel, in orange we also plot the counter-factual excess variance after correcting for the extensive margin of home bias. In the right panel, in orange we plot the counter-factual excess variance after correcting the intensive margin of home bias.
(a) Adjusting Extensive
(b) Adjusting Intensive
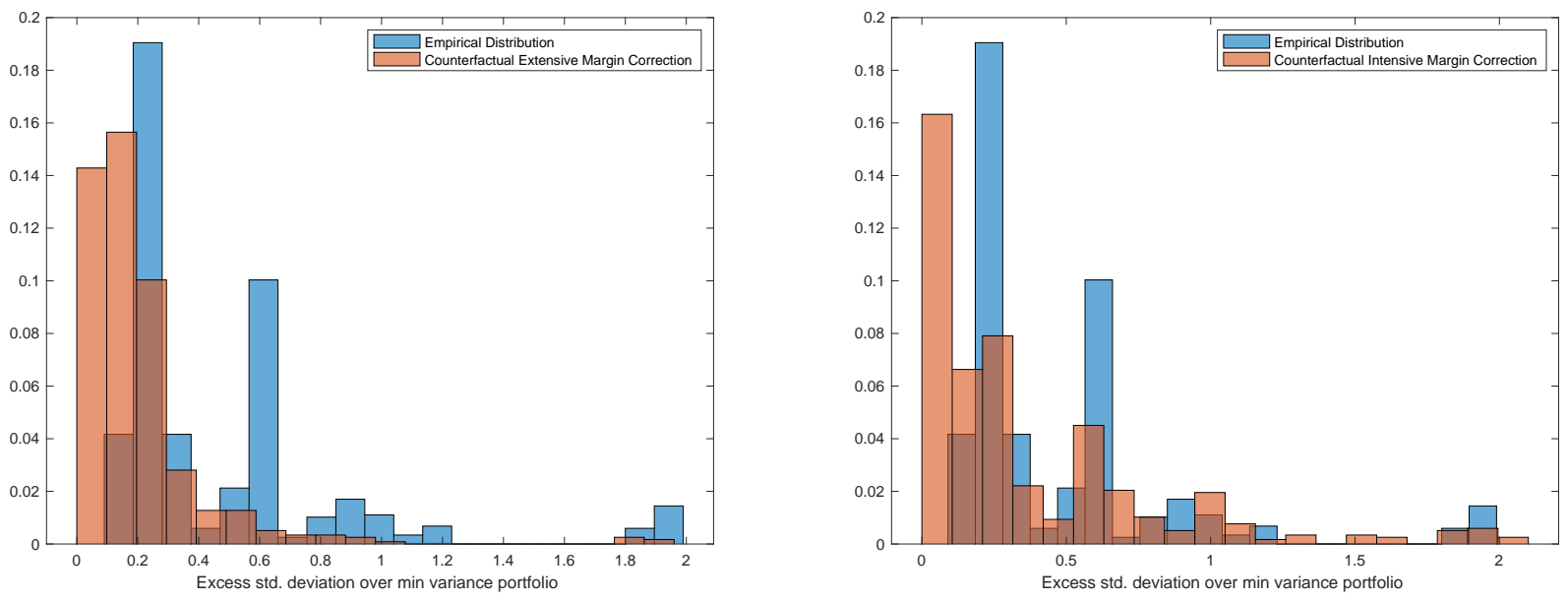

\subsection{Stylized Facts: Correlation with equity holdings and credit}

So far we have focused on sovereign bond holdings that give the best coverage of banks over time in the EBA data. However, our model can be applied to other asset classes as well. 
Since the EBA has released data on bank holdings of equity and credit exposures for a few specific dates (2012Q4, 2013Q2 and 2013Q4), in this section we show that bank holdings of bank sovereign debt are highly correlated with both. Thus, the predictions of the model and the empirical tests on sovereign debt holdings can be extended to other parts of the bank portfolio. In particular we run the following regression:

$$
\text { ShareSovEE } A_{b, c, t}=\beta \text { SharenonSovEE } A_{b, c, t}+\alpha_{b}+\alpha_{c, t}+\varepsilon_{b c t}
$$

where ShareSovEE $A_{b, c, t}$ is the share of EEA country $c$ in bank b's portfolio of sovereign debt in quarter $t$; Sharenon SovEE $A_{b, c, t}$ is a share of either equity or credit exposure computed

in the same way as the share of sovereign bonds. Finally $\alpha_{b}$ and $\alpha_{c, t}$ are bank and destination country-time fixed-effects respectively. The results are presented in Table 4.

We start from a simple OLS regression in column (1) and increasingly saturate the model with time, bank and destination country-time fixed-effects (columns 2-4). The correlation between the share of sovereign bonds and equity (or credit) is about $0.7(0.78)$ and the estimated coefficient is stable across specifications, even in the most saturated model. These results suggest that the choice of a bank to invest in a foreign country drives the whole portfolio allocation across asset classes, so that analysing the sovereign bond portfolio is a good proxy for other parts of the portfolio.

\subsection{Stylized Facts: Home Bias in Information}

The previous section analyzed the basic structure of banks' portfolios. In this section, we turn our attention to the basic structure of the typical bank's forecast precision. The main finding is that while there is a lot of heterogeneity in the precision of banks' forecasts, there is a clear home bias in information precision: for a given bank, home forecasts are significantly more precise than foreign ones.

We examine whether forecasts about future domestic sovereign yields are more or less 
accurate than forecasts of foreign sovereign yields. One way to look at this is to see if, for a given sovereign, domestically domiciled forecasters are more accurate than foreign forecasters. Moreover, since we have data on both foreign and domestic forecasts for the same forecaster, we can also compare the accuracy of home and foreign forecasts for a given forecaster. This is a powerful test of whether individual forecasters indeed have superior information about home yields (Bae et al. (2008)). We run the following panel regression:

$$
\overline{S F E}\left(Y 10_{b c t}\right)=\beta H o m e_{b c}+\alpha_{b}+\alpha_{c}+\varepsilon_{b c t}
$$

where $\overline{S F E}\left(Y 10_{b c t}\right)$ is bank $b$ 's average squared forecast error on the 3-month ahead forecast of country c's 10-year yields over our sample period, $H_{o m e}$ is a dummy variable that equals one when country $c$ is the "home" country for forecaster $b$. We allow for both forecaster and destination country fixed effects, $\alpha_{b}$ and $\alpha_{c}$.

Table 5 shows the estimates. The sample contains 85 banks that make forecasts on a total of 14 separate countries. Moving from columns (1) to (3) we progressively introduce forecaster and destination country fixed effects. The forecaster fixed effects allow us to estimate, within each forecaster, the relative precision of forecasts of home relative to foreign yields; this eliminates concerns about the potential selection of ex-ante better forecasters into only forecasting their home country. Destination country fixed effects absorb the aggregate ability of all forecasters to forecast specific countries; this controls for the possibility that all banks make better forecasts for some bigger or more important countries and for differences in the overall level of uncertainty in different countries' yields.

In all three specifications, we find that home forecasts are significantly more precise than foreign forecasts. The effects we find are both statistically and economically significant. The estimates in column (1) imply that home forecasters have an average squared forecast error about one-third of a standard deviation smaller than that of foreign forecasters. Controlling for forecaster fixed effects, the coefficient doubles in magnitude, suggesting that the effect 
is even stronger within forecasters (column (2)). Including a fixed effect for the destination country, and thus controlling for the average uncertainty around each country, the coefficient on the Home dummy remains virtually unchanged.

Thus, we conclude that banks exhibit an advantage in forecasting domestic relative to foreign sovereign yields. This observation motivates the basic premise of the model we develop in the next section, where banks endogenously become better informed about home yields in equilibrium. We then use the model to derive additional, precise implications about the relationship between point forecasts and portfolio holdings, and then take them to the data in the following section.

\section{Model}

In this section, we turn our attention to a model that can explain the stylized facts we have documented. We consider a simple three period model where agents can trade risky and risk-free assets and can acquire costly information about the asset payoffs. In period 0 agents choose their information acquisition strategy, and in period 1 new information arrives according to the chosen information strategy, agents update their beliefs and form optimal portfolios. In period 3 shocks realize and the agents consume the resulting returns on their portfolios. To keep things tractable, we work with generic "risky" assets with uncertain payoffs, but those can be viewed as long-term bonds which have uncertain payoffs due to uncertainty in their future price.

There are $N$ different countries of equal size, with a continuum of agents of mass $\frac{1}{N}$ living in each. There are $N$ risky assets, one associated with each country, and a risk-free savings technology with an exogenous rate of return $R^{f}$. Thus, in period 1 agent $i$ in country $j$ faces the budget constraint

$$
W_{1 j}^{(i)}=\sum_{k=1}^{N} P_{k} x_{j k}^{(i)}+b_{j}^{(i)}
$$

where $P_{k}$ is the price of the risky asset of country $k, x_{j k}^{(i)}$ are the portfolio holdings of risky 
assets, $b_{j}^{(i)}$ the holdings of the risk-free asset and $W_{1 j}^{(i)}$ is the investable wealth of the agent. It is useful to rewrite the budget constraint in terms of portfolio shares $\alpha_{j k}^{(i)}=\frac{P_{k} x_{j k}^{(i)}}{W_{1 j}^{(i)}}$, instead of the absolute holdings $x_{j k}^{(i)}$, in which case the budget constraint can be expressed as

$$
1=\sum_{k=1}^{N} \alpha_{j k}^{(i)}+\frac{b_{j}^{(i)}}{W_{1 j}^{(i)}}
$$

Each asset yields a stochastic payoff $D_{k}$, and hence the return on agent $i$ 's portfolio is

$$
R_{j}^{p,(i)}=\sum_{k=1}^{N} \alpha_{j k}^{(i)} \frac{D_{k}}{P_{k}}+\frac{b_{j}^{(i)}}{W_{1 j}^{(i)}} R=\boldsymbol{\alpha}_{j}^{(i)^{\prime}} \mathbf{R}+\frac{b_{j}^{(i)}}{W_{1 j}^{(i)}} R^{f}
$$

where bold letters denote $N$-by-1 vectors, $R_{k}=\frac{D_{k}}{P_{k}}$ is the gross return on asset $k$, and the $k$-th element of $\mathbf{R}$. Using the portfolio return, we can express agent $i$ 's period 2 (terminal) wealth as $W_{2 j}^{(i)}=W_{1 j}^{(i)} R_{j}^{p,(i)}$. To reduce clutter, from now we will suppress the $i$ index if there is no chance of confusion.

In period 0, agents choose their information acquisition strategy, which helps them reduce the uncertainty in the stochastic asset payoffs $\mathbf{d}$. We assume that the payoffs follow a joint Normal distribution: $\mathbf{d} \sim N\left(\mu_{d}, \Sigma_{d}\right)$. For tractability purposes, we assume that the variance matrix is diagonal, and thus fundamentals of different countries are independent of one another. This assumption has no effect on the qualitative results of the model, and could be relaxed by introducing a factor structure to payoffs. Intuitively, if we were to introduce a global factor (or more generally common factors), then learning about that factor would not affect the relative portfolio weights of different assets. It is the differential learning about individual country factors that drives portfolio concentration and home bias. Thus, for the sake of clarity of the exposition, we consider a framework where we abstract from common factors, and simply focus on the agent's incentives to learn about country-specific factors.

Agents can purchase two types of costly information. First, as in Merton (1987), we assume that the knowledge of the unconditional distribution of the asset payoffs is not available to the agents for free, but rather they have to "purchase" their priors. In particular, 
the agents know that the return distribution is joint normal with a known diagonal variance matrix $\Sigma_{d}$, but do not know the values of the mean returns of the different assets. They can purchase information about the unconditional mean of each element of $\mathbf{d}$ separately, at a fixed cost $c$. Crucially, we assume that without acquiring this prior information on the unconditional mean of the payoffs of a given asset, the agents will not hold any of that asset. This is the Merton (1987) view of information, which postulates that agents must first acquire the basic information about an asset, before holding any of it.

We view this as a modeling device for the standard due diligence procedures and initial vetting that a bank engages in before acquiring a new asset. When investing in a new country for the first time, the risk-management team of the bank must create a risk model to determine the specific capital charges for the new bond (Saunders and Cornett (2013)). The banks' lawyers and accounting team examine the bond prospectus to ensure that the bond is legitimate. ${ }^{14}$ Thus, overall, there are substantial fixed costs with each new asset added to the portfolio. We model this fixed cost as having to do with the unconditional distribution of returns of the asset. This is a useful abstraction that captures the idea that, before acting on the general understanding of the asset's returns, the bank risk-management and legal teams need to do substantial due diligence. Without having done such initial due diligence for asset $k$, the agents will not enter that market, thus setting $\alpha_{k}=0$. Once the due diligence has been done and an asset has been added to the portfolio though, it can be flexibly adjusted without the need for paying a fixed cost again (as it is also true in the real world).

In addition to learning the unconditional distribution of payoffs, the agents can also purchase unbiased signals about the actual realization of the different payoffs $d_{k}$ :

$$
\eta_{j k}^{(i)}=d_{j k}+u_{j k}^{(i)}
$$

where $u_{j k}^{(i)} \sim i i d N\left(0, \sigma_{u_{j k}}^{(i) 2}\right)$. The precision of these signals is not exogenously given, but the agents choose it optimally, subject to an increasing and convex cost $C(\kappa)$ of the total amount

\footnotetext{
${ }^{14}$ See Federal Reserve guideline for bank examiners (found here).
} 
of information, $\kappa$, encoded in their chosen signals. Information, $\kappa$, is measured in terms of entropy units (Shannon (1948)). This is the standard measure of information flow in information theory and is also widely used by the economics and finance literature on optimal information acquisition (e.g. Sims (2003), Van Nieuwerburgh and Veldkamp (2010)). It is defined as the reduction in uncertainty, measured by the entropy of the unknown asset payoffs vector $\mathbf{d}$, that occurs after observing the vector of noisy signals $\boldsymbol{\eta}_{j}^{(i)}=\left[\eta_{j 1}, \ldots, \eta_{j N}\right]^{\prime}$ :

$$
\kappa=H\left(\mathbf{d} \mid \mathcal{I}_{j}^{(i)}\right)-H\left(\mathbf{d} \mid \mathcal{I}_{j}^{(i)}, \boldsymbol{\eta}_{j}^{(i)}\right)
$$

$H(X)$ denotes the entropy of random variable $X$ and $H(X \mid Y)$ is the entropy of $X$ conditional on knowing $Y .{ }^{15}$ Moreover, $\mathcal{I}_{j}^{(i)}$ is the prior information set of agent $i$, which contains both the subset of priors on $\mathbf{d}$ which he has purchased and the public information that is observed for free by all agents (such as the equilibrium prices). Thus, $\kappa$ measures the total amount of information about the vector of asset returns $\mathbf{d}$ contained in the vector of private signals, $\boldsymbol{\eta}_{j}^{(i)}$, over and above the agent's priors and any publicly available information. Given our assumption that asset payoffs are uncorrelated across countries, we can express $\kappa$ as the sum of the informational contents of the country-specific signals $\eta_{j 1}^{(i)}, \ldots, \eta_{j N}^{(i)}: \kappa=\kappa_{1}+\cdots+\kappa_{N}$. The information content of each individual signal is similarly defined as the information about the underlying fundamental over and above the publicly available information:

$$
\kappa_{k}=H\left(d_{k} \mid \mathcal{I}_{j}^{(i)}\right)-H\left(d_{k} \mid \mathcal{I}_{j}^{(i)}, \eta_{j k}^{(i)}\right)
$$

Finally, we also assume that agents have an arbitrarily small information advantage over their home assets, which is modeled by assuming that they receive a free, unbiased signal with exogenously fixed precision $\frac{1}{\sigma_{\eta}^{2}}$ about the domestic asset payoff. As it will become clear later, this gives home information a slight edge that the optimal information choice endogenously amplifies, and leads to home bias in portfolios. This wedge needs to be only arbitrarily

\footnotetext{
${ }^{15}$ Entropy is defined as $H(X)=-E(\ln (f(x)))$, where $f(x)$ is the probability density function of X.
} 
small, hence for simplicity we introduce it exogenously. However, it can be endogenized in a number of ways, such as for example by modeling the fact that the agents can also make non-tradable investments in the home country, and hence value home information slightly more than foreign information. ${ }^{16}$

After observing all of their chosen signals, the agents use standard Bayesian updating to update their beliefs about the asset payoffs. Thus, acquiring more informative signals $\boldsymbol{\eta}_{j}^{(i)}$ reduces the posterior variance of the asset payoffs. This is the Grossman and Stiglitz (1980) view of information, and can also be seen as an "intensive" margin of information acquisition, whereas the Merton (1987) view represents the "extensive" margin of information acquisition. Our model combines both of these views of information. Intuitively, the framework captures the idea that before buying an asset banks need to pay an upfront cost for an initial due diligence study that would reveal the unconditional distribution of payoffs of the given asset. Once that is done, they can then also form a dedicated analysis team that can devote additional resources to following the fundamentals of that country, and produce more or less precise forecasts of the particular future realization of the payoff $d_{k}$.

Lastly, the agents maximize expected CRRA utility $u(W)=\frac{W_{j}^{1-\gamma}}{1-\gamma}$ over their terminal wealth $W_{2 j}^{(i)}$. We solve the model by backward induction, by starting with the optimal portfolio choice in period 1 , and then solving for the optimal information choice in period 0 .

\subsection{Period 1: Portfolio Choice}

In period 1, agents observe the unconditional payoff distributions and additional informative signals $\boldsymbol{\eta}$ that they chose in period 0, and update their beliefs accordingly. Conditional on those beliefs, agents pick the portfolio composition that maximizes their expected utility:

$$
\max _{\boldsymbol{\alpha}_{j}^{(i)^{\prime}}} E\left[\frac{\left(W_{2 j}^{(i)}\right)^{1-\gamma}}{1-\gamma} \mid \mathcal{I}_{j}^{(i)}, \boldsymbol{\eta}_{j}^{(i)}\right]
$$

\footnotetext{
${ }^{16}$ See for example Nieuwerburgh and Veldkamp (2006) and Valchev (2017)
} 
s.t.

$$
\begin{gathered}
W_{2 j}^{(i)}=\underbrace{\left(W_{0}-\Psi_{j}^{(i)}-C\left(K_{j}^{(i)}\right)\right)}_{W_{1 j}^{(i)}} R_{j}^{p,(i)}=W_{1 j}^{(i)}\left(\boldsymbol{\alpha}_{j}^{(i)^{\prime}} \mathbf{R}+\left(1-\boldsymbol{\alpha}_{j}^{(i)^{\prime}} \mathbf{1}\right) R^{f}\right) \\
\alpha_{j k}^{(i)}=0 \text { for all } k \notin \mathcal{F}_{j}^{(i)}
\end{gathered}
$$

where $\mathcal{F}_{j}^{(i)}$ is the set of countries for which agent $i$ has purchased information about the unconditional distribution of returns, $\Psi_{j}^{(i)}=\left|\mathcal{F}_{j}^{(i)}\right| c$ is the total expenditure on prior information, $C\left(K_{j}^{(i)}\right)$ is the cost of the additional noisy signals, and thus $W_{1 j}^{(i)}=W_{0}-\Psi_{j}^{(i)}-C\left(\kappa_{j}^{(i)}\right)$ is the wealth of the agent at the beginning of period 1. This is his investable wealth - it is equal to his initial wealth, $W_{0}$, minus all information costs he incurred in period 0 . Substituting the constraint out, the objective function becomes

$$
\max _{\boldsymbol{\alpha}_{j}^{(i)^{\prime}}} \frac{\left(W_{1 j}^{(i)}\right)^{1-\gamma}}{1-\gamma} E\left[\exp \left((1-\gamma) r_{j}^{(i), p}\right) \mid \mathcal{I}_{j}^{(i)}, \boldsymbol{\eta}_{j}^{(i)}\right]
$$

where lower case letters denote logs. Next, we follow Campbell and Viceira (2001) and use a second-order Taylor expansion to express the log portfolio return as

$$
r_{j}^{(i), p} \approx r^{f}+\boldsymbol{\alpha}_{j}^{(i)^{\prime}}\left(\mathbf{r}-r^{f}+\frac{1}{2} \operatorname{diag}\left(\hat{\Sigma}_{j}\right)\right)-\frac{1}{2} \boldsymbol{\alpha}_{j}^{(i)^{\prime}} \hat{\Sigma}_{j} \boldsymbol{\alpha}_{j}^{(i)}
$$

where we have used $\hat{\Sigma}_{j}=\operatorname{Var}\left(\mathbf{r} \mid \mathcal{I}_{j}^{(i)}, \boldsymbol{\eta}_{j}^{(i)}\right)$ to denote the posterior variance of the risky asset payoffs. We have dropped the subscript $i$ to reduce clutter, but stress that posterior variances could potentially differ among agents within the same country. For future reference, note that since $\mathbf{r}=\mathbf{d}-\mathbf{p}$ and $\mathbf{p}$ is in the information set of the agent, it follows that $\hat{\Sigma}_{j}=\operatorname{Var}\left(\mathbf{d} \mid \mathcal{I}_{j}^{(i)}, \boldsymbol{\eta}_{j}^{(i)}\right)$.

We can then plug (6) into the objective function (5), and take expectations over the resulting log-normal variables and obtain a closed-form objective function. Taking first order 
conditions, and solving for the portfolio shares $\boldsymbol{\alpha}_{j}$ yields:

$$
\boldsymbol{\alpha}_{j}=\frac{1}{\gamma} \hat{\Sigma}_{j}^{-1}\left(E\left(\mathbf{r}_{t+1} \mid \mathcal{I}_{j}^{(i)}, \boldsymbol{\eta}_{j}^{(i)}\right)-r^{f}+\frac{1}{2} \operatorname{diag}\left(\hat{\Sigma}_{j}\right)\right)
$$

Given the assumption that all factors are independent, this simplifies further so that the holdings of agent $i$ in country $j$ of asset $k$ are:

$$
\alpha_{j k}^{(i)}=\frac{E\left(r_{k} \mid \mathcal{I}_{j}^{(i)}, \eta_{j k}^{(i)}\right)-r^{f}+\frac{1}{2} \hat{\sigma}_{k r}^{2}}{\gamma \hat{\sigma}_{j k}^{2}}
$$

where $\hat{\sigma}_{j k}^{2}$ is the $k$-th diagonal element of $\hat{\Sigma}_{j}$. Thus, agents invest more heavily in assets they

expect to do better (high $E\left(r_{k} \mid \mathcal{I}_{j}^{(i)}, \eta_{j k}^{(i)}\right)$ ), and invest less in more uncertain assets that have higher posterior variance of log-returns.

\subsection{Asset Market Equilibrium}

In addition to the informed traders, there are also noise traders that trade the $N$ assets for reasons orthogonal to the fundamentals $\mathbf{d}$. From a technical perspective, they are needed in order to ensure that there are more shocks than asset prices, otherwise the prices will fully span the uncertainty facing the agents and thus unravel private information (GrossmanStiglitz paradox). In reality, a substantial amount of bonds is held for liquidity and hedging purposes, and to the extent to which those reasons for holdings bonds are unrelated to the financial payoffs of the bonds, they are modeled by $z_{k}$. Market clearing requires that the sum of the asset demands of all informed traders equals the net supply arising from noise trading,

$$
\sum_{j=1}^{n} \int \frac{W_{1 j}^{(i)}}{N} \alpha_{j k}^{(i)} d i=z_{k}
$$

where we denote the net effect of noise trading for asset $k$ as $z_{k} \sim i i d N\left(\mu_{z k}, \sigma_{z k}^{2}\right)$. One can think of $z_{k}$ as the "effective" supply of asset $k$, it is the amount of bonds that needs to be absorbed by the informed traders. 
We guess and verify that the equilibrium price is linear in the states and of the form

$$
p_{k}=\bar{\lambda}_{k}+\lambda_{d k} d_{k}+\lambda_{z k} z_{k} .
$$

Thus, the price itself contains useful information about the unknown $d_{k}$, and the agents can extract the following informative signal from it,

$$
\tilde{p}_{k}=d_{k}+\frac{\lambda_{z k}}{\lambda_{d k}}\left(z_{k}-\mu_{z}\right) .
$$

The agents combine this signal together with their private signals $\eta$ and the priors, and use Bayes' rule to form posterior beliefs, leading to the following expressions for the conditional expectation and variance:

$$
\begin{gathered}
E\left(d_{k} \mid \mathcal{I}_{j}^{(i)}, \boldsymbol{\eta}_{j}^{(i)}\right)=\left(\frac{1}{\sigma_{d k}^{2}}+\left(\frac{\lambda_{d k}}{\lambda_{z k}} \sigma_{z k}\right)^{2}+\frac{1}{\sigma_{\eta j k}^{2}}\right)^{-1}\left(\frac{\mu_{d k}}{\sigma_{d k}^{2}}+\left(\frac{\lambda_{d k}}{\lambda_{z k} \sigma_{z k}}\right)^{2} \tilde{p}_{k}+\frac{1}{\sigma_{\eta j k}^{2}} \eta_{j k}^{(i)}\right) \\
\hat{\sigma}_{j k}^{2}=\left(\frac{1}{\sigma_{d k}^{2}}+\left(\frac{\lambda_{d k}}{\lambda_{z k}} \sigma_{z k}\right)^{2}+\frac{1}{\sigma_{\eta j k}^{2}}\right)^{-1}
\end{gathered}
$$

We can then substitute back everything into the market clearing conditions and solve for the equilibrium asset price's coefficients. The details are given in the Appendix A, and here we just highlight the resulting coefficients $\lambda_{d k}$ and $\lambda_{z k}$ which determine the informativeness of the prices. The resulting coefficients are:

$$
\begin{gathered}
\lambda_{z k}=-\gamma \bar{\sigma}_{k}^{2}\left(1+\frac{\bar{\phi}_{k} \bar{q}_{k}}{\gamma^{2} \sigma_{z}^{2}}\right) \\
\lambda_{d k}=\bar{\sigma}_{k}^{2} \bar{q}_{k}\left(1+\frac{\bar{\phi}_{k} \bar{q}_{k}}{\gamma^{2} \sigma_{z}^{2}}\right)
\end{gathered}
$$

where

$$
\bar{q}_{k}=\sum_{j} \frac{W_{1 j}^{(i)}}{N} \frac{\hat{\sigma}_{j k}^{2}}{\hat{\sigma}_{j k}^{2}+\sigma_{e}^{2}} \frac{1}{\sigma_{\eta_{j k}}^{2}}
$$


is a wealth weighted-average of the signal precisions of all market participants,

$$
\bar{\sigma}_{k}^{2}=\left(\frac{1}{N} \sum_{j} \frac{W_{1 j}^{(i)}}{\hat{\sigma}_{j k}^{2}}\right)^{-1}
$$

is the wealth weighted-average posterior variance of returns.

\subsection{Period 0: Information Choice}

Information choice is made ex-ante, before asset markets open and agents see the actual realizations of their private signals $\eta$. However, they fully take into account how their information choices affect their future conditional beliefs, optimal portfolio holdings and resulting wealth. Given that all country factors are independent, the time 0 objective function of the agent becomes a sum of the expected benefits of acquiring information for each country separately. Details are given in the Appendix, but by doing appropriate evaluations of expectations, we can show that the time 0 expectation of the log-objective function of an agent in country $j$ is given by:

$$
U_{0 j}=(1-\gamma) \ln \left(\frac{W_{1 j}}{\gamma-1}\right)+\sum_{k \in \mathcal{F}_{j}} \frac{1}{2} \ln \left(1+(\gamma-1) \frac{\sigma_{k}^{2}}{\hat{\sigma}_{j k}^{2}}\right)+\frac{\gamma-1}{2} \sum_{k \in \mathcal{F}_{j}} \frac{m_{k}^{2}}{\hat{\sigma}_{j k}^{2}+(\gamma-1) \sigma_{k}^{2}}
$$

where $m_{k}=E\left(d_{k}-p_{k}\right)$ is the ex-ante unconditional expected excess return on asset $k$ based only on prior information on the unconditional distribution of asset payoffs. The set $\mathcal{F}_{j}$ is the set of countries for which the agent has decided to purchase priors and hence holds positive investments in. Again, we have suppressed the $i$ index, but variances and countries chosen to invest in could differ among agents within the same country.

We solve the information choice problem in three steps. First, we solve for the optimal allocation of intensive information, given a choice of total intensive information acquired $K$ 
and the set of countries that the agent has chosen to learn about $\mathcal{F}_{j}$, by solving:

$$
\max _{\hat{\sigma}_{j k}^{2}} \sum_{k \in \mathcal{F}_{j}} \frac{1}{2} \ln \left(1+(\gamma-1) \frac{\sigma_{k}^{2}}{\hat{\sigma}_{j k}^{2}}\right)+\frac{\gamma-1}{2} \sum_{k \in \mathcal{F}_{j}} \frac{m_{k}^{2}}{\hat{\sigma}_{j k}^{2}+(\gamma-1) \sigma_{k}^{2}}
$$

s.t.

$$
\sum_{k \in \mathcal{F}_{j}} \kappa_{k} \leq K
$$

The details are given in the Appendix, but the main result is that as long as ex-ante Sharpe Ratios are less than one (as is true in the data), the problem is strictly convex in the information allocated to any given country $\left(\kappa_{k}\right)$ and hence agents find it optimal to allocate all intensive information to the payoffs of a single asset. Given our assumption that agents receive a free signal on the payoff of the domestic assets, unless there is a lot of asymmetry among countries, so that certain countries are ex-ante seen as much superior investments, the optimal choice will be to acquire information only about the home asset: for agents in country $j, \kappa_{j}=K$ and $\kappa_{j^{\prime}}=0$ for all $j^{\prime} \neq j$. Formally, we can prove that agents are always weakly better informed about home assets than foreign agents, and in the case of a symmetric world they are strictly better informed, because in that case it is clear that all agents only learn about their respective domestic assets.

Proposition 1. Home Bias in Information: If ex-ante Sharpe Ratios are less than one, $\frac{E\left(d_{k}-p_{k}\right)}{\sqrt{\operatorname{Var}\left(d_{k}-p_{k}\right)}}<1$ for all $k$, learning amplifies the home bias in information, so that

$$
\kappa_{j j} \geq \kappa_{j^{\prime} j}
$$

for all $j \neq j^{\prime}$ for all agents in each country. In a symmetric world where all countries are ex-ante identical, the inequality is strict.

Proof. Intuition sketched in the text, details in the Appendix.

The basic idea behind the Proposition is that since the learning problem is convex, the 
additional free signal agents receive on home assets means that if anyone chooses to learn about the home asset, it must be the case that the home agents are also learning about it they have a comparative advantage in learning about that asset. If they are indeed learning about the home asset, then they are also strictly better informed than any of the foreign agents (since they also have the free signal). If they are not learning about the home assets, then no one else is either, and thus everyone is equally uninformed. In a symmetric world, agents always find it optimal to learn about their home asset, so the inequality is strict.

Next, taking the optimal allocation of intensive information as given, we solve for the optimal choice of the total intensive information acquired $K$. Since all additional information is allocated to a single asset, call it $k$, we just need to figure out what is the optimal precision of information about that asset. The first-order condition for this choice simplifies to:

$$
\frac{C^{\prime}\left(K_{j}^{*}\right)}{W-C\left(K_{j}^{*}\right)-\Psi_{j}}=\frac{(\gamma-1)\left[4 \hat{\sigma}_{k}^{2}\left(m_{k}^{2}+\sigma_{k}^{2}-(\gamma-1) m_{k} \sigma_{k}^{2}\right)+4(\gamma-1) \sigma_{k}^{4}-\hat{\sigma}_{k}^{6}-2(\gamma-1) \sigma_{k}^{2} \hat{\sigma}_{k}^{4}\right]}{8\left(\hat{\sigma}_{k}^{2}+(\gamma-1) \sigma_{k}^{2}\right)^{2}}
$$

Given a convex information cost function $C(K)$, this defines a unique solution for total intensive information $K_{j}^{*}$ acquired by agents in country $j$.

Last, we determine the optimal number of countries about which agents choose to purchase information on the unconditional distribution of asset payoffs, i.e. the extensive margin information choice. The cost of adding an asset to the learning (and hence investment) portfolio is a fixed amount $c$ that agents need to pay for the due diligence study. The gain is derived from expecting to earn positive excess returns on the asset (on average). The detailed characterization of this choice is presented in the Appendix, but the key intuition for why it is uniquely determined is the fact that the marginal cost of adding an additional asset to the learning portfolio is increasing.

This happens for two reasons. First, marginal utility of investable wealth $W_{1 j}$ is declining (see the term $\ln \left(\frac{W_{1 j}}{\gamma-1}\right)$ in eq. (9)), but the more resources an agent spends on due diligence studies $\left(\Psi_{j}\right)$ the fewer are left for portfolio investment (lower $W_{1 j}$ ). As a result, even though all due diligence studies cost the same fixed amount $c$ in terms of wealth, each additional 
study has an increasing utility cost because of the concavity of the log function. Second, lower investable wealth also translates to a lower optimal choice of $K_{j}^{*}$, through its effect on the LHS of equation (11), and therefore lower utility from the asset holdings about which the agent acquires additional information. Thus, increasing the breadth of the portfolio carries increasing costs. As a result, unless the fixed cost of acquiring priors is very small relative to the agent's initial wealth, it is unlikely that the agent will learn about all available assets. This generates sparse portfolios, with the level of sparseness varying with the wealth level of the agent, as formalized in the next section.

\subsection{Model Implications}

The model is able to match the stylized portfolio facts that we documented earlier. For all propositions in this section, we focus on symmetric equilibria where we assume all countries are ex-ante the same and all agents within the same country follow the same optimal policy. Moreover, the ex-ante Sharpe Ratios are less than one $\frac{E\left(d_{k}-p_{k}\right)}{\sqrt{\operatorname{Var}\left(d_{k}-p_{k}\right)}}=\frac{E(d-p)}{\sqrt{\operatorname{Var}(d-p)}}<1$, so that the information problem of the agents is guaranteed to be strictly convex.

Proposition 2. The equilibrium portfolio holdings of an agent in country $j, \boldsymbol{\alpha}_{j}=\left[\alpha_{j 1}, \ldots, \alpha_{j N}\right]$, display the following key features:

1. Sparseness: There exists a threshold wealth level $\bar{W}$, such that if the initial wealth of agents is less than that, $W_{0}<\bar{W}$, the agents do not invest in all available foreign assets, i.e. $\alpha_{j k}=0$ for some $k$ for all $j$.

2. Sparseness decreases with wealth: The number of countries $k$ for which $\alpha_{j k}=0$ is decreasing with $W_{1 j}^{(i)}$, i.e. the size of the agent's investment portfolio

Proof. Intuition sketched in the text, details in the Appendix B.

The first result, sparseness, is a consequence of the two-tiered information structure of the model and the fact that acquiring extensive information faces increasing costs, but fixed benefits (the ex-ante expected utility of adding an additional asset to the portfolio in the 
symmetric world is the same for all foreign assets). An agent will add new assets to their portfolio up to the point at which the cost of doing a new initial country study exceeds the gain of doing so. The gain is pretty straightforward - the agent likes to add new assets to his portfolio because they offer positive excess returns and diversification benefits.

As discussed earlier, even though the financial cost of an extra due diligence study is a constant amount $c$, the cost in utility terms is increasing because (i) marginal utility is declining in investable wealth and (ii) each decrease in investable wealth decreases the amount of intensive information $K^{*}$ acquired. In the symmetric equilibrium of Proposition 1 , the gain of learning about an additional country is constant, hence there is an optimal number of foreign countries that the agent will learn about. This could be zero (i.e. only invest in the home country) if the agent's wealth is sufficiently low. The utility cost of an additional due diligence studies, however, is decreasing in the initial wealth of the agent, hence richer agents would learn about at least some of the foreign countries, and possibly all foreign countries given enough wealth. This last observation is also behind the second result that the sparseness of the portfolio is decreasing in the agent's wealth.

Lastly, to understand the result on the average foreign bias, consider how the positive foreign holdings of the agent relate to one another. Recall that agents find it optimal to specialize in acquiring additional intensive information only about the home asset. Thus, for all foreign assets they rely only on publicly available information and their priors. In a symmetric world where all countries are ex-ante identical, the relative informativeness of the equilibrium prices of the different assets will be the same as well. Therefore, the posterior variance of foreign assets payoffs, which only relies on priors and the information contained in prices, is the same. Thus, the average portfolio weight of a foreign asset $k$ is:

$$
E\left(\alpha_{j k}\right)=\frac{m-r^{f}+\frac{1}{2} \tilde{\sigma}^{2}}{\gamma \tilde{\sigma}^{2}}
$$

where $m=m_{k}$ for all $k$ is the expected excess return on the risky assets, and $\tilde{\sigma}=\operatorname{Var}(d-p \mid p)$ 
is the perceived variance conditional on publicly available information. As a result, the average foreign bias of any non-zero foreign holding is the same, and is in fact zero.

Lastly, note that combining the results of Propositions 1 and 2 implies that the equilibrium portfolios are biased towards home assets due to both an extensive and an intensive margin, just as in the data. First, the agents do not invest in all available foreign countries (result 1 in Proposition 2), and second, they specialize intensive information acquisition in home assets (see Proposition 1). Thus, the model can fit all of the salient portfolio facts we documented earlier.

Perhaps the key economic insight is that the model features both increasing returns to intensive margin information, and decreasing returns to extensive margin information. The increasing returns in intensive information come about due to a strong feedback between portfolio holdings and additional precision of beliefs: the more precise one's beliefs, the higher the average exposure to that asset, and thus the higher the incentives to procure more information about it. On the other hand, knowing that all intensive information is going to be allocated to just one asset, there is no such strong feedback effect between the extensive margin of information acquisition and portfolio holdings. As a result, the model can feature both a strong home bias among assets held in positive proportions (because any private information provision is dedicated to the home asset), and sparse foreign portfolios, because at lower levels of wealth it is not optimal to purchase priors about (and thus invest in) all foreign countries. Both of these forces contribute to the overall home bias of the portfolios, as is also true in the data.

\section{Empirical Tests}

As we have seen, the model with two-tiered information cost structure can rationalize the stylized portfolio facts documented in Section 2.2, but is this mechanism empirically relevant? To examine this question, we directly test the model's key implications in the data. We derive 
two sets of implications that are crucial to the inner-workings of the mechanism, and examine each of them in the following sections. First we test whether portfolio sparseness is associated with sparseness in information (the extensive margin). Second, we test whether optimism and accuracy of forecasts matter for actual portfolio holdings (the intensive margin).

\subsection{Extensive Margin of Information and Portfolios}

In our model, the sparseness of portfolios follows directly from the sparseness of information. In our two-tiered information structure, we follow Merton (1987) and assume that agents only hold assets for which they have done due diligence and performed an initial country study. Due to the fixed costs incurred, agents may optimally choose not to acquire any information about certain countries and, as a result, decide not to invest anything in them, leading to sparse portfolios. In this section, we examine whether sparseness of information is indeed associated with sparseness of portfolios in our dataset.

To begin with, we examine whether a bank's portfolio holdings of sovereign debt of a given country correlate with whether or not the bank produces a forecast for that country's

bond yields. Since every bank invests in its domestic country, we restrict the sample to foreign holdings only and estimate the following regression:

$$
\text { Share }_{b c t}=\beta \text { ForeignFcst }_{b c t}+\mu_{b t}+\gamma_{c t}+\varepsilon_{b c t}
$$

where Share $_{b c t}$ is the share of foreign country $c$ in bank b's portfolio at time $t$ and ForeignFcst bct $_{\text {t }}$ is a dummy variable that equals 1 if bank $b$ makes a 10-year yield forecast about country $c$ at time $t$, and 0 otherwise. Finally, $\mu_{b t}$ and $\gamma_{c t}$ represent bank-time and country-of-destinationtime fixed effects, respectively.

The results are presented in Table 6, Panel A: when a bank makes a forecast for a foreign country, its foreign sovereign exposure to that country is 10-11\% higher, i.e. about two standard deviations higher (see Table 3, Panel B). We progressively saturate the model 
with fixed effects in order to make sure that unobserved heterogeneity does not affect the main result. We start with no fixed effects in column (1), we then add time (column (2)), bank (column (3)), destination country (column (4)), bank-time (column (5)), and finally country-time (column (6)) fixed effects. Thus in the last specification we are only using variation across foreign holdings for the same bank at the same time, absorbing all other country-level shocks. In all cases, the coefficient on ForeignFcst bct $_{\text {is }}$ remarkably stable. The results thus indicate that information acquisition is strongly correlated with bank foreign exposures, consistent with our model's implications.

Next, in Panel B of Table 6, we specifically examine if sparseness of portfolios is associated with sparseness in information sets. To this purpose, we replace the continuous dependent variable, Share $_{b, c, t}$, with a dummy, $\mathbf{1}\left(\right.$ Share $\left._{b, c, t}\right)$, that is equal to 1 if bank $b$ holds any positive amount of country c's sovereign debt, and zero otherwise The results indicate that if a bank makes a foreign forecast for a country it is around $20-40 \%$ more likely to hold sovereign bonds from that country. The results are both highly statistically and economically significant, supporting the idea that collecting information on a particular country is predictive of investing in it.

\subsection{Intensive Margin of Information and Portfolios}

Next, we look at the specific relationship between the precision of beliefs and portfolio shares in the data. In the model, the optimal portfolio share for an asset $k$ for which an agent pays the fixed information cost $c$ is

$$
\alpha_{k}=\frac{E\left(r_{k} \mid \mathcal{I}_{j}^{(i)}, \eta_{j k}^{(i)}\right)-r^{f}}{\gamma \hat{\sigma}_{k}^{2}}+\frac{1}{2 \gamma}
$$

The equation puts specific non-linear restrictions on the relationship between portfolio shares, expected returns and the precision of those expectations as summarized in Proposition 3.

Proposition 3. (Comparative Statics) The optimal portfolio share of asset $k$ in the 
portfolio of agent $i$ in country $j$ is

1. Increasing in the conditional expected return $E\left(r_{k} \mid \mathcal{I}_{j}^{(i)}, \eta_{j k}^{(i)}\right)$ :

$$
\frac{\partial \alpha_{j k}}{\partial E\left(r_{k} \mid \mathcal{I}_{j}^{(i)}, \eta_{j k}^{(i)}\right)}=\frac{1}{\gamma \hat{\sigma}_{j k}^{2}}>0
$$

\section{Increasing in the precision of beliefs:}

$$
\frac{\partial \alpha_{j k}}{\partial \hat{\sigma}_{k}^{2}}=-\frac{E\left(r_{k} \mid \mathcal{I}_{j}^{(i)}, \eta_{j k}^{(i)}\right)-r^{f}}{\gamma \hat{\sigma}_{k}^{4}}<0 \Longleftrightarrow E\left(r_{k} \mid \mathcal{I}_{j}^{(i)}, \eta_{j k}^{(i)}\right)-r^{f}>0
$$

3. More elastic to expected returns the higher the precision of beliefs:

$$
\frac{\partial^{2} \alpha_{j k}}{\partial E\left(r_{k} \mid \mathcal{I}_{j}^{(i)}, \eta_{j k}^{(i)}\right) \partial \hat{\sigma}_{j k}^{2}}=-\frac{1}{\gamma \hat{\sigma}_{j k}^{4}}<0
$$

Proof. Follows directly from derivating equation (7).

Thus, as demonstrated in Proposition 3, agents will hold more of a given asset the more optimistic they are about its returns $\left(\frac{\partial \alpha}{\partial E(r)}>0\right)$, and the more certain they are in their expectation, i.e. the lower the variance of their beliefs is $\left(\frac{\partial \alpha}{\partial \sigma^{2}}<0\right)$. Moreover, the portfolio sensitivity to beliefs $\left(\frac{\partial \alpha}{\partial E(r)}\right)$ increases with the precision of beliefs: when a bank becomes optimistic about a country, it reallocates more of its portfolio towards that country the more precise its beliefs about that country are $\left(\frac{\partial^{2} \alpha}{\partial E(r) \partial \sigma^{2}}<0\right) .{ }^{17}$

We seek to test these implications of the model by estimating the following regression:

$$
\text { Share_lt } t_{b c t}=\beta_{1} \overline{S F E}\left(Y 10_{b c t}\right)+\beta_{2} Y 10_{b c t}+\beta_{3} \overline{S F E}\left(Y 10_{b c t}\right) \times Y 10_{b c t}+\mu_{b}++\gamma_{c t}+\varepsilon_{b c t}
$$

where Share_l $t_{b c t}$ is the share of country $c$ in bank $b$ 's portfolio of long-term debt (i.e. with

\footnotetext{
${ }^{17}$ Although the above equations and comparative statics are only partial equilibrium expressions, they are still useful to gain intuition as the results carry over to general equilibrium as well. For more details see Appendix C.
} 
residual maturity of five years or more) in quarter $t ; Y 10_{b c t}$ is the 3-month ahead forecast made by bank $b$ regarding the 10-year yield on country c's sovereign debt averaged over quarter $t$, and $\overline{S F E}\left(Y 10_{b c t}\right)$ is bank $b$ 's average squared forecast error regarding $Y 10 .{ }^{18}$ Finally, $\mu_{b}$ and $\gamma_{c t}$ are bank and destination country-time fixed effects, respectively. ${ }^{19}$

As per Proposition 3, the model puts sign restrictions on the $\beta$ coefficients in the above regression. First, it implies that $\beta_{1}<0$ because portfolio shares are decreasing in the uncertainty of banks' forecasts; hence, the higher is the average squared forecast error of a forecast about a particular country, the lower the bank's investment in that country. Second, $\beta_{2}<0$ since investments in a given country's sovereign debt are increasing in the expected return on that sovereign bond (higher expected yields are associated with lower future prices, and hence lower expected returns). And third, $\beta_{3}>0$ since the sensitivity of portfolio shares to expected returns is increasing in the precision of the return forecast. In the above regression, the sensitivity of the portfolio share to changes in the forecast of future yields is given by

$$
\frac{\partial S h a r e \_l t_{b c t}}{\partial Y 10_{b c t}}=\beta_{2}+\beta_{3} \overline{S F E}\left(Y 10_{b c t}\right)
$$

Since we expect $\beta_{2}<0$ and the model predicts that more precise information (lower $\overline{S F E}$ ) would further add to this negative effect, we therefore expect $\beta_{3}$ to be positive. To sum up, the model predicts that $\beta_{1}<0, \beta_{2}<0$, and $\beta_{3}>0$.

The results are presented in Tables 7 and 8 . The two tables differ as to their treatment of holdings of domestic sovereign debt. Table 7 does not try to explain the large amount

\footnotetext{
${ }^{18}$ We focus on the share of long-term debt because the forecast of 10 -year yields is most relevant for returns on long-term bonds. However, Table 11 in the Appendix D shows that the results are robust if we use the share of total debt, including short-term debt (i.e. 3 month, 1 year, 2 years and 3 years residual maturities). We also use the 1-year ahead forecast, rather than 3 month ahead, for robustness in Table 12. Results remain very similar.

${ }^{19}$ We cannot include bank-time fixed effects in equation (14) as we did for the extensive margin regressions in equation (12) due to the limited sample size (around 200 versus more than 5000 observations). The sample is reduced because for the intensive margin regression we need banks to have both positive holdings in the EBA dataset and a 10-year yield forecast in Consensus Economics for the same destination country. Moreover, we cannot cluster standard errors at either bank or country level with such a low number of clusters, as the estimated variance-covariance matrix would not be consistent (although the estimated coefficients are still significant even when we cluster). We use White-robust standard errors instead.
} 
of home bias present in portfolios, but rather restricts the sample to the foreign portion of portfolios. This provides a direct test of information-based theories of the home bias. In fact, while most existing theories are silent on potential heterogeneity among foreign holdings, the information model has a rich set of implication about those as well. In Table 8 we use instead the full sovereign portfolio, including the share of home assets, but we separately control for it through a Home dummy. For comparison purposes, the sample of banks is restricted to be the same in both tables, so that these are banks that have at least one foreign exposure (and a foreign forecast) in addition to the domestic one.

In Table 7 we find that, consistent with the predictions of our model, more precise information impacts portfolio holdings both directly and indirectly: more accuracy not only leads to higher holdings (direct effect $\beta_{1}$ ), but it also amplifies the effect of expectations on holdings $\left(\beta_{2}\right)$, making portfolio shares more sensitive to changes in forecasts (amplification effect $\beta_{3}$ ). The results are similarly significant across all four columns, which increasingly saturate the regression with fixed effects to control for unobserved heterogeneity, starting from no fixed effect in column (1) to bank and country-time fixed effects in column (4). In the last column, we are essentially using only variation within a bank's portfolio, taking out aggregate destination country shocks in each time period. Controlling for country-specific shocks to bank holdings of sovereign debt is important during our sample period (2010-2013) because the European sovereign debt crisis affected different countries at different times. ${ }^{20}$

The estimated coefficients are also economically significant. The effect of uncertainty on portfolio holdings is large: the estimates in column (4) of Table 7 indicate that a one standard deviation decrease in $\overline{S F E}(0.32)$ at the average 10 -year yield forecast $(3.75 \%)$ is associated with an increased portfolio share of 1.56 percentage points, which is about $20 \%$ of the average foreign portfolio holdings. ${ }^{21}$ The economic significance of the amplification effect of information precision $\left(\beta_{3}\right)$ is also sizable. To illustrate this, we return to the previous

\footnotetext{
${ }^{20}$ The results are not driven by the debt crisis, since excluding exposure to peripheral countries (GIIPS) does not affect the estimated coefficient (see Table 13 in the Appendix D).

${ }^{21}$ The relevant summary statistics for the sample on the intensive margin are found in Table 3, Panel C, third to last row.
} 
example: had the point forecast of the 10-year yield been one standard deviation below the mean (i.e., at $2 \%$ ), the implied portfolio share would have increased by an additional 5.7 percentage points, more than three times the 1.56 percentage points increase found earlier.

Table 8 shows that the results still hold when we use the full sovereign debt portfolio of banks, including their over-weighted domestic holdings. The coefficient on the Home dummy is always large (20-30 percentage points), statistically significant and explains a large fraction of the overall variation in the total portfolios (the adjusted $R^{2}$ in column 1 of Table 8 is 40 percentage points higher than in column 1 of Table 7). Taken together, these results also suggest that, while relevant, information frictions alone cannot explain the full extent of the home bias we observe in the data. Thus, we can conclude that information heterogeneity matter particularly for understanding the composition of foreign holdings, but are only part of the story of the apparent heavy preference for home assets.

A potential concern in these regressions is reverse causality. Perhaps banks acquire foreign investments for reasons orthogonal to their beliefs about expected future yields, and only afterward produce a forecast for Consensus, the survey provider. First of all, we think that this is unlikely, because of the large and significant $\beta_{2}$ and $\beta_{3}$ estimates which tell us that portfolio holdings not only change with the beliefs about future yields, but also that the elasticity to such changes in beliefs depends on the objective precision of the forecast. Moreover, as an additional test to rule out reverse causality, we re-estimate Table 7 and 8 by computing a time-varying average squared forecast error $\left(\overline{S F E}_{b, c, t-1}\right)$ using the information set available as of $(t-1)$ rather than on the whole Consensus sample period (2006-2013). That is, we regress long-term holding of sovereign debt $\left(\right.$ Share_l $\left.l t_{b, c, t}\right)$ in $2010 \mathrm{Q} 1$ on $\overline{S F E}_{b, c, t-1}$, calculated using the bank $b$ forecast for country $c$ between 2006Q1-2009Q4, and so on. Results are qualitatively similar and are presented in Table 14.

A potential concern in these regressions is reverse causality. The only way in which our results could be driven by reverse causality would be the following: a bank acquires foreign investments for reasons orthogonal to its beliefs about expected future yields, and only 
afterwards invests resources to acquire precise information about the investment. Importantly, it would have to be the case that a larger investment would trigger the bank to be both more optimistic, and to later obtain very precise information about it. First of all, this backward reasoning is very unlikely since banks make investments on the basis of their beliefs on risk-adjusted returns, and not vice versa. Moreover, as an additional test to rule out this possibility, we re-estimate Table 7 and 8 by computing a time-varying average squared forecast error $\left(\overline{S F E}_{b, c, t-1}\right)$ using the preexisting information set available at $t-1$, rather than on the whole Consensus sample period (2006-2013). That is, we regress long-term holding of sovereign debt $\left(\right.$ Share_l $\left.t_{b, c, t}\right)$ in 2010Q1 on the past accuracy of forecasts, $\overline{S F E}_{b, c, t-1}$, which is calculated using the bank $b$ forecast for country $c$ between 2006Q1-2009Q4. Results are qualitatively similar and are presented in Table 14.

A related worry is that banks report untruthful forecasts to Consensus, and reporting biases could be explaining the covariance behind $\beta_{2}$. This hypothesis seems unlikely because of how good the forecasts tend to be on average (see Table 3). There is certainly a lot of objective information encoded in the reported forecasts, and what is more, banks react to the objective precision of the forecasts as per the significant $\beta_{3}$. Similarly, if a bank reported overly optimistic forecasts in an attempt to inflate the asset's price while the bank is selling it, we would observe the opposite correlation between holdings and forecasts $\left(\beta_{2}>0\right)$ than what we estimate $\left(\hat{\beta}_{2}<0\right)$.

Our results also suggest that the relationship between portfolios and beliefs is not behavioral, but rather conforms with how an optimal Bayesian agent would behave. The primary reason for this conclusion is the large and significantly positive $\beta_{3}$ estimate, which suggests that agents properly perceive which of their forecasts are more precise and appropriately react more to changes in the more precise forecasts. A behavioral agent might still react to point forecasts (i.e. $\beta_{2}<0$ as we find), but is unlikely to display a higher sensitivity to changes in point forecasts that are objectively more precise (i.e. we would expect $\beta_{3}=0$ ). 


\section{Conclusion}

In this paper we study whether information frictions can explain the heterogeneity in banks' sovereign debt holdings. We go beyond the standard home versus foreign divide, and analyze the entire portfolio allocation. In order to empirically connect information frictions with portfolio holdings, we use banks' sovereign exposure data from EBA, matched with banks' forecasts from Consensus Economics. The empirical findings suggest that information frictions are at the core of both extensive (which countries to invest in) and intensive (how much to allocate in each chosen country) margins of the portfolio allocation problem.

Regarding the extensive margin, we show that the typical bank sovereign portfolio is sparse: it has a large exposure to its domestic sovereign and no exposure to most foreign countries. Moreover, having acquired information on a certain country strongly predicts the likelihood of investing in such country. We also confirm previous results that banks have more precise information about their own domestic country.

Turning to the intensive margin, we show that optimism and accuracy of information about a country strongly predict higher portfolio holdings of that country's sovereign debt. Moreover, we also document that precise information amplifies the sensitivity of portfolio holdings to changes in expectations: for a given improvement in bank's forecasts about a country, receiving more accurate information predicts a larger portfolio allocation towards that country's sovereign debt.

Finally, we show that a model with information frictions and a two-tiered information structure with a fixed-cost of acquiring information can rationalize all of these findings: stylized facts about portfolio sparseness, the connection between information acquisition and sparseness (extensive margin), and the role of optimism and information precision in determining the intensity of portfolio holdings (intensive margin). 


\section{References}

Adler, Michael and Bernard Dumas, "International portfolio choice and corporation finance: A synthesis," The Journal of Finance, 1983, 38 (3), 925-984.

Ahearne, A.G., W.L. Griever, and F.E. Warnock, "Information costs and home bias: an analysis of US holdings of foreign equities," Journal of International Economics, 2004, 62 (2), 313-336.

Altavilla, Carlo, Marco Pagano, and Saverio Simonelli, "Bank Exposures and Sovereign Stress Transmission," Review of Finance, 2017, 21 (6).

Ammer, John, Sara Holland, David Smith, and Francis Warnock, "U.S. International Equity Investment," Journal of Accounting Research, 2012, 50 (5).

Bae, Kee-Hong, Rene' Stulz, and Hongping Tan, "Do Local Analysts Know More? A Cross-Country Study of the Perfomance of Local Analysts and Foreign Analysts," Journal of Financial Economics, 2008, (88), 581-606.

Brennan, M.J. and H.H. Cao, "International portfolio investment flows," Journal of Finance, 1997, pp. 1851-1880.

Burger, John D and Francis E Warnock, "Diversification, Original Sin, and International Bond Portfolios," 2003. FRB International Finance Discussion Paper 755.

Campbell, John Y and Luis M Viceira, "Who Should Buy Long-Term Bonds?," American Economic Review, 2001, pp. 99-127.

_, Laurent E Calvet, and Paolo Sodini, "Appendix for" Down or Out: Assessing the Welfare Costs of Household Investment Mistakes"," Journal of Political Economy, 2007.

Coeurdacier, Nicolas and Helene Rey, "Home bias in open economy financial macroeconomics," Journal of Economic Literature, 2013, 51 (1), 63-115. 
- and Pierre-Olivier Gourinchas, "When bonds matter: Home bias in goods and assets," Journal of Monetary Economics, 2016, 82, 119-137.

Cornaggia, Jess, Kimberly Rodgers Cornaggia, and Ryan D Israelsen, "Where the heart is: information production and the home bias," 2017. Working Paper.

Dahlquist, Magnus, Lee Pinkowitz, René M Stulz, and Rohan Williamson, "Corporate governance and the home bias," Journal of Financial and Quantitative Analysis, 2003, $38(01), 87-110$.

DeMarco, Filippo, "Bank Lending and the European Sovereign Debt Crisis," Journal of Financial and Quantitative Analysis, forthcoming, 2017.

_ and Marco Macchiavelli, "The political origin of home bias: The case of Europe," 2015.

Dickstein, Michael J and Eduardo Morales, "What do exporters know?," National Bureau of Economic Research, 2015.

Dziuda, Wioletta and Jordi Mondria, "Asymmetric Information, Portfolio Managers, and Home Bias," Review of Financial Studies, 2012, 25 (7), 2109-2154.

ESRB, "Report on the regulatory treatment of sovereign exposures," 2015.

Fidora, Michael, Marcel Fratzscher, and Christian Thimann, "Home bias in global bond and equity markets: the role of real exchange rate volatility," Journal of International Money and Finance, 2007, 26 (4), 631-655.

French, K.R. and J.M. Poterba, "Investor Diversification and International Equity Markets," American Economic Review, 1991, 81 (2), 222-226.

Gârleanu, Nicolae, Stavros Panageas, and Jianfeng Yu, "Impediments to Financial Trade: Theory and Applications," Technical Report, National Bureau of Economic Research 2016. 
Goetzmann, W.N. and A. Kumar, "Equity Portfolio Diversification*," Review of Finance, 2008, $12(3), 433-463$.

Grinblatt, Mark and Matti Keloharju, "How distance, language, and culture influence stockholdings and trades," The Journal of Finance, 2001, 56 (3), 1053-1073.

Grossman, Sanford J and Joseph E Stiglitz, "On the impossibility of informationally efficient markets," The American economic review, 1980, 70 (3), 393-408.

Guiso, Luigi and Tullio Jappelli, "Financial literacy and portfolio diversification," 2008. EIEF Working Paper 0812.

Hatchondo, C.J., "Asymmetric Information and the Lack of portfolio diversification," International Economic Review, 2008, 49 (4), 1297-1330.

Hau, Harald and Helene Rey, "Home bias at the fund level," The American Economic Review P\&P, 2008, 98 (2), 333-338.

Heathcote, J. and F. Perri, "The international diversification puzzle is not as bad as you think," Journal of Political Economy, 2013, 121 (6), 1108-1159.

Huberman, G., "Familiarity breeds investment," Review of financial Studies, 2001, 14 (3), 659-680.

Ivković, Z. and S. Weisbenner, "Local does as local is: Information content of the geography of individual investors' common stock investments," The Journal of Finance, 2005, 60 (1), 267-306.

Kimball, M. and T. Shumway, "Investor sophistication and the home bias, diversification, and employer stock puzzles," Available at SSRN 1572866, 2010.

Lenz, Christian, Karl Lins, and Francis Warnock, "Do Foreigners Invest Less in Poorly Governed Firms?," Review of Financial Studies, 2009, 22 (8), 3245-3285. 
Maggiori, Matteo, Brent Neiman, and Jesse Schreger, "International Currencies and Capital Allocation," National Bureau of Economic Research, 2018.

Malloy, C.J., "The geography of equity analysis," The Journal of Finance, 2005, 60 (2), 719-755.

Massa, M. and A. Simonov, "Hedging, familiarity and portfolio choice," Review of Financial Studies, 2006, 19 (2), 633-685.

Merton, R.C., "A Simple Model of Capital Market Equilibrium with Incomplete Information," Journal of Finance, 1987, 42 (3), 483-510.

Mondria, J., "Portfolio choice, attention allocation, and price comovement," Journal of Economic Theory, 2010, 145 (5), 1837-1864.

Morales, Eduardo, Gloria Sheu, and Andres Zahler, "Extended gravity," National Bureau of Economic Research, 2017.

Nieuwerburgh, S. Van and L. Veldkamp, "Information immobility and the home bias puzzle," The Journal of Finance, 2009, 64 (3), 1187-1215.

_ and _, "Information Acquisition and Under-Diversification," Review of Economic Studies, 2010, $77(2), 779-805$.

Nieuwerburgh, Stijn and Laura Veldkamp, "Inside information and the own company stock puzzle," Journal of the European Economic Association, 2006, 4 (2-3), 623-633.

Obstfeld, Maurice and Kenneth Rogoff, "The six major puzzles in international macroeconomics: is there a common cause?," in "NBER Macroeconomics Annual 2000, Volume 15," MIT press, 2001, pp. 339-412.

Ongena, Steven, Alexander Popov, and Neeltje VanHoren, "The invisible hand of the government: Moral suasion during the European sovereign debt crisis," Working Paper, 2016. 
Popov, Alexander and Neeltje Van Horen, "Exporting Sovereign Stress: Evidence from Syndicated Bank Lending During the Euro Area Sovereign Debt Crisis," Review of Finance, 2014.

Portes, Richard and Helene Rey, "The determinants of cross-border equity flows," Journal of international Economics, 2005, 65 (2), 269-296.

Saunders, Anthony and Marcia Millon Cornett, Financial Institutions Management: A Risk Management Approach, Vol. 8, McGraw-Hill Education, 2013.

Serrat, Angel, "A dynamic equilibrium model of international portfolio holdings," Econometrica, 2001, 69 (6), 1467-1489.

Shannon, CE, "A mathematical theory of communication," The Bell System Technical Journal, 1948, 27 (3), 379-423.

Shin, Chae Hee, "An Industrial Organization Approach to International Portfolio Diversification: Evidence from the U.S. Mutual Fund Families," Technical Report, Finance and Economics Discussion Series, Federal Reserve Board 2014.

Sims, C.A., "Implications of rational inattention," Journal of Monetary Economics, 2003, $50(3), 665-690$.

Solnik, Bruno, "Equity home bias and regret: an international equilibrium model," 2008.

Stockman, Alan C and Harris Dellas, "International portfolio nondiversification and exchange rate variability," Journal of international Economics, 1989, 26 (3-4), 271-289.

Tesar, L.L. and I.M. Werner, "The internationalization of securities markets since the 1987 crash," Brookings-Wharton papers on financial services, 1998, 1, 421-429.

Valchev, Rosen, "Dynamic Information Acquisition and Portfolio Bias," 2017. 
von Gaudecker, Hans-Marting, "How does household portfolio diversification vary with financial literacy and financial advice?," The Journal of Finance, 2015, 70 (2), 489-507. 
Table 1: Home Bias Index: Intensive and Extensive Margin

This table contains summary statistics of the home bias index and the two counterfactual home bias indexes.

\begin{tabular}{lcccc} 
& Average & $25^{\text {th }}$ pct. & $50^{\text {th }}$ pct. & $75^{\text {th }}$ pct. \\
\hline HB & 0.61 & 0.39 & 0.72 & 0.84 \\
Adjusting Extensive margin & 0.25 & 0.06 & 0.23 & 0.43 \\
Adjusting Intensive margin & 0.37 & 0.08 & 0.29 & 0.62 \\
\hline \hline
\end{tabular}

Table 2: Variable Definition

This table contains the definition of variables used in all the empirical analyses.

\begin{tabular}{llll} 
Variable & Definition & TimePeriod & Data source \\
\hline Y10 $0_{b, c, t}$ & $\begin{array}{l}\text { 3-months ahead forecast for } 10-\text { year sovereign bond } \\
\text { yield of country } c \text { from forecaster } b \text { at time } t\end{array}$ & $2006 \mathrm{M} 9-$ & Consensus \\
$\operatorname{SFE}\left(X_{b, c, t}\right)$ & Squared Forecast Error $=\left(\mathbb{E}_{t-h}\left(X_{t}\right)-X_{t}\right)^{2}$ & $2006 \mathrm{M} 9-$ & Consensus \\
& & $2014 \mathrm{M} 12$ & \\
$\overline{S F E}\left(X_{b, c}\right)$ & Average SFE $=\sum_{t} S F E\left(X_{b, c, t}\right)$ & $2006 \mathrm{M} 9-$ & Consensus \\
& & $2014 \mathrm{M} 12$ & \\
Home $_{b, t}$ & Dummy $=1$ for domestic forecast & & Consensus \\
ForeignFcst $_{b, c, t}$ & $\begin{array}{l}\text { Dummy }=1 \text { if forecaster } b \text { makes a 10-year yield } \\
\text { forecast for country } c \text { at time } t\end{array}$ & EBA-Consensus \\
ShareSovEEA $_{b, c, t}$ & $\begin{array}{l}\text { Share of sovereign bonds of country } c \text { (EEA only) in } \\
\text { bank } b \text { sovereign portfolio }\end{array}$ & $2010 \mathrm{Q} 1-2013 \mathrm{Q} 4$ & EBA \\
\hline \hline
\end{tabular}




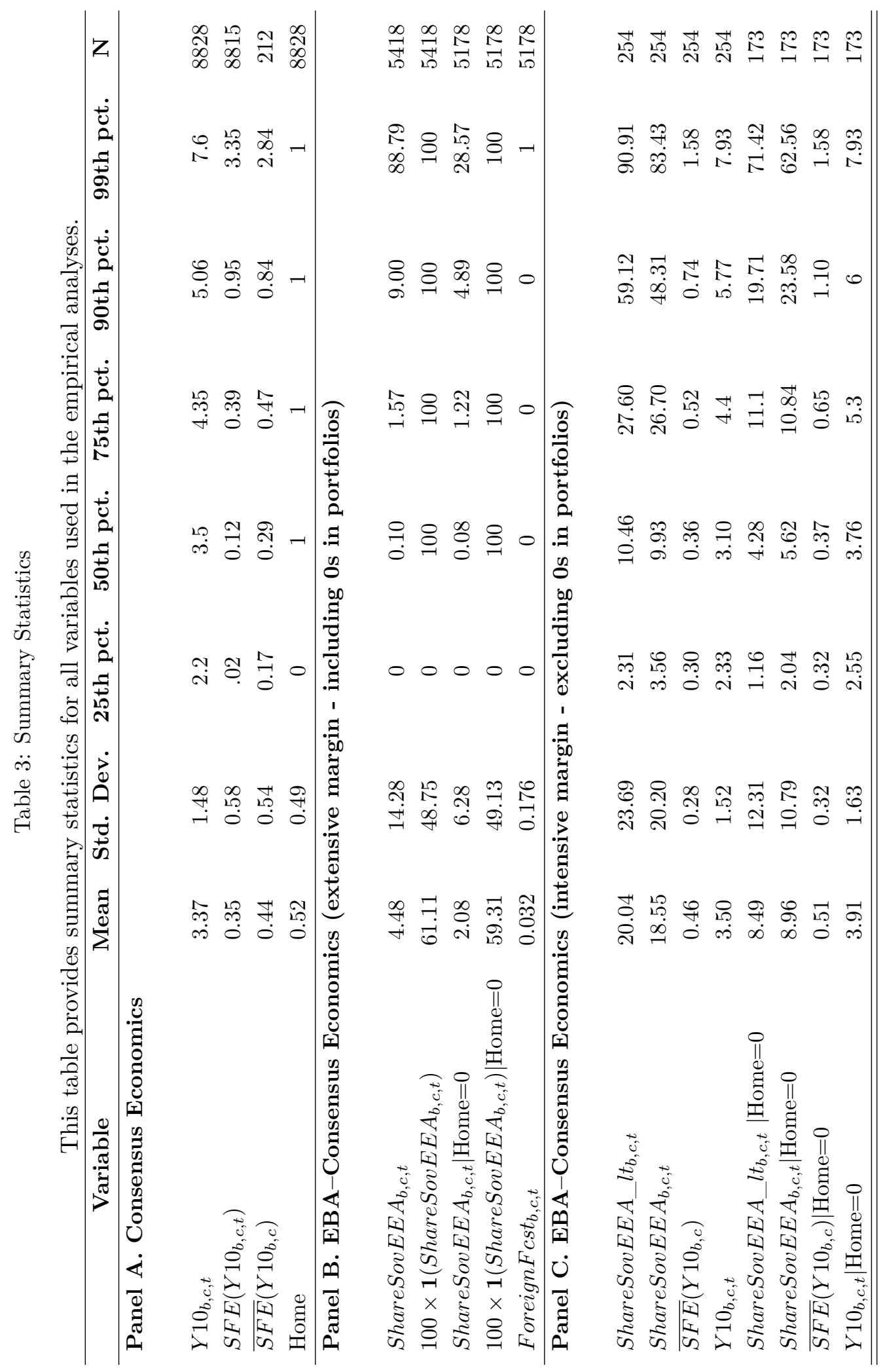


Table 4: Correlation with equity holdings and credit

This table provides estimates for equation (1). The dependent variable is the share of EEA country $c$ sovereign bonds in bank $b$ sovereign portfolio in quarter $t$ (2012Q4-2013Q4). ShareEquityEE $A_{b, c, t}$ is the share of EEA country $c$ equity in bank $b$ total equity portfolio and ShareCredEE $A_{b, c, t}$ is the share of credit to EEA country $c$ as a fraction of bank $b$ total credit. Standard errors are reported in parentheses and are clustered at the bank level. ***,**,* indicate statistical significance at $1 \%$, $5 \%$, and $10 \%$, respectively.

Panel A. Correlation with equity holdings

\begin{tabular}{lcccc}
\hline & $(1)$ & $(2)$ & $(3)$ & $(4)$ \\
\hline Share EquityEE $A_{b, c, t}$ & $0.712^{* * *}$ & $0.712^{* * *}$ & $0.712^{* * *}$ & $0.694^{* * *}$ \\
& $(0.031)$ & $(0.031)$ & $(0.031)$ & $(0.032)$ \\
\hline Observations & 6544 & 6544 & 6544 & 6544 \\
Adj. $R^{2}$ & 0.762 & 0.758 & 0.758 & 0.769 \\
N of Banks & 108 & 108 & 108 & 108 \\
N of Destination Countries & 30 & 30 & 30 & 30 \\
\hline & & & & \\
Panel B. Correlation with credit exposures & & & \\
\hline & $(1)$ & $(2)$ & $(3)$ & $(4)$ \\
\hline & & & & \\
ShareCredEE $A_{b, c, t}$ & $0.785^{* * *}$ & $0.785^{* * *}$ & $0.785^{* * *}$ & $0.775^{* * *}$ \\
& $(0.026)$ & $(0.026)$ & $(0.026)$ & $(0.027)$ \\
\hline Observations & 7134 & 7134 & 7134 & 7134 \\
Adj. $R^{2}$ & 0.779 & 0.775 & 0.775 & 0.782 \\
$\mathrm{~N}$ of Banks & 119 & 119 & 119 & 119 \\
$\mathrm{~N}$ of Destination Countries & 30 & 30 & 30 & 30 \\
\hline Time FE & no & yes & yes & - \\
Bank FE & no & no & yes & yes \\
Destination Country-Time FE & no & no & no & yes \\
\hline \hline
\end{tabular}


Table 5: Are Home Forecasters Better?

This table provides estimates for equation (2). The dependent variable is the average squared forecast error of bank $b$ regarding the 3 -month ahead forecast on country $c$ 's 10 -year yield $(\overline{S F E}(\mathrm{Y} 10)$ ). Home is a dummy equal to one if the forecaster is domestic, zero otherwise. Standard errors are reported in parentheses and are clustered at the forecaster level. $* * *, * *, *$ indicate statistical significance at 1\%, 5\%, and 10\%, respectively.

\begin{tabular}{lccc}
\hline & $(1)$ & $(2)$ & $(3)$ \\
\hline Home & $\begin{array}{c}-0.188^{* * *} \\
(0.070)\end{array}$ & $\begin{array}{c}-0.369^{* * *} \\
(0.127)\end{array}$ & $\begin{array}{c}-0.358^{* * *} \\
(0.113)\end{array}$ \\
\hline Observations & 212 & 160 & 160 \\
N of Forecasters & 85 & 33 & 33 \\
N of Destination Countries & 14 & 14 & 14 \\
Forecaster FE & no & yes & yes \\
Destination Country FE & no & no & yes \\
\hline \hline
\end{tabular}


Table 6: Extensive Margin: Foreign Sovereign Exposures and Foreign Forecast

This table provides the estimates for equation (12). The dependent variable is the share of EEA country $c$ in bank $b$ sovereign portfolio in Panel A and a dummy equal to one if bank $b$ holds a positive amount of sovereign bonds of EEA country $c$ in Panel B. The sample is restricted to exposures to foreign countries only. ForeignFcst ${ }_{b, c, t}$ is a dummy equal to one if bank $b$ makes a 10-year yield forecast for country $c$ in year $t$ and zero otherwise. Standard errors are reported in parentheses and are clustered at the bank level. ***,**,* indicate statistical significance at 1\%, 5\%, and $10 \%$, respectively.

Panel A: Dependent variable ShareSovEE $A_{b, c, t}$ for non-domestic exposures

\begin{tabular}{lcccccc}
\hline & $(1)$ & $(2)$ & $(3)$ & $(4)$ & $(5)$ & $(6)$ \\
\hline ForeignFcst & $11.30^{* * *}$ & $11.30^{* * *}$ & $11.11^{* * *}$ & $10.06^{* *}$ & $10.14^{* *}$ & $10.30^{* *}$ \\
& $(3.703)$ & $(3.708)$ & $(3.979)$ & $(3.851)$ & $(3.941)$ & $(4.000)$ \\
\hline Observations & 5170 & 5170 & 5170 & 5170 & 5170 & 5170 \\
Adj. $R^{2}$ & 0.103 & 0.102 & 0.127 & 0.254 & 0.239 & 0.210 \\
N of Banks & 35 & 35 & 35 & 35 & 35 & 35 \\
N of Destination Countries & 23 & 23 & 23 & 23 & 23 & 23 \\
\hline
\end{tabular}

Panel B: Dependent variable $100 \times \mathbf{1}\left(\right.$ ShareSovE $\left.E A_{b, c, t}\right)$ for non-domestic exposures

\begin{tabular}{lcccccc}
\hline & $(1)$ & $(2)$ & $(3)$ & $(4)$ & $(5)$ & $(6)$ \\
\hline ForeignFcst & $40.24^{* * *}$ & $40.43^{* * *}$ & $28.92^{* * *}$ & $19.46^{* *}$ & $19.89^{* *}$ & $20.13^{* *}$ \\
& $(4.305)$ & $(4.327)$ & $(4.417)$ & $(8.218)$ & $(8.339)$ & $(8.490)$ \\
\hline Observations & 5170 & 5170 & 5170 & 5170 & 5170 & 5170 \\
Adj. $R^{2}$ & 0.0207 & 0.0264 & 0.228 & 0.386 & 0.387 & 0.379 \\
N of Banks & 35 & 35 & 35 & 35 & 35 & 35 \\
N of Destination Countries & 23 & 23 & 23 & 23 & 23 & 23 \\
\hline Time FE & no & yes & yes & yes & - & - \\
Bank FE & no & no & yes & yes & yes & - \\
Destination country FE & no & no & no & yes & - & - \\
Country-Time FE & no & no & no & no & yes & yes \\
Bank-Time FE & no & no & no & no & no & yes \\
\hline \hline
\end{tabular}


Table 7: Intensive Margin - Foreign Exposures

This table provides the estimates for equation (14). The dependent variable is the share of EEA country $c$ sovereign bonds in bank $b$ sovereign portfolio of long-term debt $(>5$ years residual maturity). $Y 10$ is the 3 -month ahead forecast made by bank b regarding the 10-year yield on country c's sovereign debt averaged over quarter $t$. $\overline{S F E}(Y 10)$ is bank $b$ 's average squared forecast error regarding $Y 10$ throughout the sample period. Standard errors are reported in parentheses and are White-robust. ${ }^{* * *}, * *, *$ indicate statistical significance at $1 \%, 5 \%$, and $10 \%$, respectively.

\begin{tabular}{lcccc}
\hline \hline & $(1)$ & $(2)$ & $(3)$ & $(4)$ \\
\hline$\overline{S F E}(Y 10)$ & $-38.55^{* * *}$ & $-38.24^{* * *}$ & $-47.07^{* * *}$ & $-33.08^{* * *}$ \\
& $(11.128)$ & $(11.337)$ & $(7.882)$ & $(9.257)$ \\
Y10 & $-5.657^{* * *}$ & $-5.904^{* * *}$ & $-4.532^{* * *}$ & $-4.561^{* *}$ \\
& $(1.357)$ & $(1.300)$ & $(0.686)$ & $(1.994)$ \\
SFE $(Y 10) \times Y 10$ & $7.073^{* * *}$ & $7.123^{* * *}$ & $7.866^{* * *}$ & $7.565^{* * *}$ \\
& $(1.925)$ & $(1.914)$ & $(1.332)$ & $(1.806)$ \\
\hline Observations & 175 & 175 & 173 & 153 \\
Adj. R & 0.162 & 0.158 & 0.748 & 0.840 \\
N of Banks & 15 & 15 & 15 & 14 \\
N of Destination Countries & 11 & 11 & 11 & 8 \\
\hline Time FE & no & yes & yes & - \\
Bank FE & no & no & yes & yes \\
Destination Country-Time FE & no & no & no & yes \\
\hline \hline
\end{tabular}


Table 8: Intensive Margin - Domestic and Foreign Exposures

This table provides the estimates for equation (14). The dependent variable is the share of EEA country $c$ sovereign bonds in bank $b$ sovereign portfolio of long-term debt $(>5$ years residual maturity). $Y 10$ is the 3 -month ahead forecast made by bank b regarding the 10-year yield on country c's sovereign debt averaged over quarter $t$. $\overline{S F E}(Y 10)$ is bank $b$ 's average squared forecast error regarding $Y 10$ throughout the sample period. Home equals one for domestic holdings, zero otherwise. Standard errors are reported in parentheses and are White-robust. ***,**,* indicate statistical significance at $1 \%, 5 \%$, and $10 \%$, respectively.

\begin{tabular}{lcccc}
\hline \hline & $(1)$ & $(2)$ & $(3)$ & $(4)$ \\
\hline$\overline{S F E}(Y 10)$ & $-34.97^{* * *}$ & $-34.93^{* * *}$ & $-30.57^{* * *}$ & $-62.99^{* * *}$ \\
& $(10.453)$ & $(10.495)$ & $(11.115)$ & $(10.138)$ \\
Y10_1 & $-5.578^{* * *}$ & $-5.897^{* * *}$ & $-3.356^{* * *}$ & $-6.937^{* *}$ \\
& $(1.343)$ & $(1.274)$ & $(0.947)$ & $(3.040)$ \\
$\overline{S F E}(Y 10) \times Y 10$ & $6.674^{* * *}$ & $6.785^{* * *}$ & $5.461^{* * *}$ & $11.70^{* * *}$ \\
& $(1.833)$ & $(1.798)$ & $(1.760)$ & $(1.874)$ \\
Home & $32.13^{* * *}$ & $31.79^{* * *}$ & $30.54^{* * *}$ & $23.94^{* * *}$ \\
\hline Observations & $(3.055)$ & $(3.076)$ & $(3.339)$ & $(2.213)$ \\
Adj. R ${ }^{2}$ & 254 & 254 & 254 & 236 \\
N of Banks & 0.537 & 0.527 & 0.746 & 0.804 \\
N of Destination Countries & 11 & 11 & 11 & 10 \\
\hline Time FE & no & yes & yes & - \\
Bank FE & no & no & yes & yes \\
Country-Time FE & no & no & no & yes \\
\hline \hline
\end{tabular}




\section{Appendix}

\section{A Solving the Model}

In period 2, the agents face the problem

$$
\max _{\boldsymbol{\alpha}_{j}^{(i)^{\prime}}} E\left[\frac{\left(W_{2 j}^{(i)}\right) 1-\gamma}{1-\gamma} \mid \mathcal{I}_{j}^{(i)}, \boldsymbol{\eta}_{j}^{(i)}\right]
$$

s.t.

$$
W_{2 j}^{(i)}=\underbrace{\left(W_{0}-\Psi_{j}^{(i)}-C\left(K_{j}^{(i)}\right)\right)}_{W_{1 j}^{(i)}} R_{j}^{p,(i)}=W_{1 j}^{(i)}\left(\boldsymbol{\alpha}_{j}^{(i)^{\prime}} \mathbf{R}+\left(1-\boldsymbol{\alpha}_{j}^{(i)^{\prime}} \mathbf{1}\right) R^{f}\right)
$$

where $\Psi_{j}^{(i)}=\sum_{k} \iota_{j k} c$ is the total expenditure of the agents in country $j$ on prior information $\left(\iota_{j k}\right.$ is 1 if the agent purchases information about the $k$-th country, and zero otherwise), and $K_{j}^{(i)}$ is the total amount of intensive information acquired. Thus, the wealth available for investing at the beginning of period 1 is

$$
W_{1 j}^{(i)}=W_{0}-\Psi_{j}^{(i)}-C\left(K_{j}^{(i)}\right)
$$

Substituting the constraint out, the maximization problem is equivalent to

$$
\max _{\boldsymbol{\alpha}_{j}^{(i)^{\prime}}} \frac{\left(W_{1 j}^{(i)}\right)^{1-\gamma}}{1-\gamma} E\left[\exp \left((1-\gamma) r_{j}^{(i), p}\right) \mid \mathcal{I}_{j}^{(i)}, \boldsymbol{\eta}_{j}^{(i)}\right]
$$

where lower case letters denote logs. Next, we follow Campbell and Viceira (2001) and use a second-order Taylor expansion to express the log portfolio return as

$$
r_{j}^{(i), p} \approx r^{f}+\boldsymbol{\alpha}_{j}^{(i)^{\prime}}\left(\mathbf{r}-r^{f}+\frac{1}{2} \operatorname{diag}\left(\hat{\Sigma}_{j}\right)\right)-\frac{1}{2} \boldsymbol{\alpha}_{j}^{(i)^{\prime}} \hat{\Sigma}_{j} \boldsymbol{\alpha}_{j}^{(i)}
$$


where we have used $\hat{\Sigma}_{j}=\operatorname{Var}\left(\mathbf{r} \mid \mathcal{I}_{j}^{(i)}, \boldsymbol{\eta}_{j}^{(i)}\right)$ to denote the posterior variance of the risky asset payoffs. For future reference, note also that since $\mathbf{r}=\mathbf{d}-\mathbf{p}$ and $\mathbf{p}$ is in the information set of the agent, it follows that $\hat{\Sigma}_{j}=\operatorname{Var}\left(\mathbf{d} \mid \mathcal{I}_{j}^{(i)}, \boldsymbol{\eta}_{j}^{(i)}\right)$.

Lastly, plugging (16) into the objective function (15) and taking expectations over the resulting log-normal variable yields the following objective function:

$$
\frac{\left(W_{1 j}\right)^{1-\gamma}}{1-\gamma} \exp \left((1-\gamma)\left(r^{f}+\boldsymbol{\alpha}^{\prime}\left(E_{1 j}(\mathbf{r})-r^{f}+\frac{1}{2} \operatorname{diag}\left(\hat{\Sigma}_{j}\right)\right)-\frac{1}{2} \boldsymbol{\alpha}^{\prime} \hat{\Sigma}_{j} \boldsymbol{\alpha}\right)+\frac{(1-\gamma)^{2}}{2} \boldsymbol{\alpha}^{\prime} \hat{\Sigma}_{j} \boldsymbol{\alpha}\right)
$$

where with a slight abuse of notation we have dropped the $i$ subscript for convenience, and use the notation $E_{1 j}()=.E\left(. \mid \mathcal{I}^{(i)}\right)$ to denote the conditional expectation of the agent using all of the information available to him at time 1.

Taking first order conditions, and solving for the portfolio shares $\boldsymbol{\alpha}$ yields:

$$
\boldsymbol{\alpha}_{j}=\frac{1}{\gamma} \hat{\Sigma}_{j}^{-1}\left(E_{1 j}(\mathbf{r})-r^{f}+\frac{1}{2} \operatorname{diag}\left(\hat{\Sigma}_{j}\right)\right)
$$

Furthermore, given the assumption that all factors are independent, this reduces to

$$
\alpha_{j k}=\frac{E_{1 j}\left(r_{k}\right)-r^{f}}{\gamma \hat{\sigma}_{j k}^{2}}+\frac{1}{2 \gamma}
$$

for all assets $k$.

\section{A.1 Asset Market Equilibrium}

We focus on symmetric equilibria, where all agents in a given country $j$ make the same information choices. The market clearing condition for asset $k$ is:

$z_{k}=\frac{1}{N} \sum_{j \in \mathcal{B}_{k}} W_{1 j} \frac{\hat{\sigma}_{j k}^{2}\left(\frac{\mu_{d k}}{\sigma_{d k}^{2}}+\left(\frac{\lambda_{d k}}{\lambda_{z k} \sigma_{z k}}\right)^{2}\left(d_{k}+\frac{\lambda_{z k}}{\lambda_{d k}}\left(z_{k}-\mu_{z k}\right)\right)+\frac{1}{\sigma_{\eta j k}^{2}} d_{k}\right)-\left(\bar{\lambda}_{k}+\lambda_{d k} d_{k}+\lambda_{z k} z_{k}\right)-r^{f}+\frac{1}{2}\left(\hat{\sigma}_{j k}^{2}\right)}{\gamma \hat{\sigma}_{j k}^{2}}$ 
where the set $\mathcal{B}_{k}$ is the set of all countries whose agents choose to purchase prior information about asset $k$. Matching coefficients, we get

$$
\bar{\lambda}_{k}=\underbrace{\left(\frac{1}{N_{k}} \sum_{j \in \mathcal{B}_{k}} \frac{W_{1 j}}{\hat{\sigma}_{j k}^{2}}\right)^{-1}}_{=\bar{\sigma}_{k}^{2}}[\underbrace{\left(\frac{1}{N_{k}} \sum_{j \in \mathcal{B}_{k}} W_{1 j}\right)}_{=\bar{\phi}_{k}}\left(\frac{\mu_{d k}}{\sigma_{d k}^{2}}-\frac{\lambda_{d k}}{\lambda_{z k} \sigma_{z k}^{2}} \mu_{z k}\right)+\sum_{j \in \mathcal{B}_{k}} \frac{W_{1 j}}{2 N}]-r^{f}
$$

where we define two useful quantities for later use -1) the (wealth-weighted) posterior variance of the average market participant in the market of asset $k, \bar{\sigma}_{k}^{2}$, and 2) the average wealth of the market participants in the market for asset $k, \bar{\phi}_{k}$. Similarly,

$$
\begin{aligned}
& \lambda_{z k}=-\gamma \bar{\sigma}_{k}^{2}\left(1+\frac{\bar{\phi}_{k} \bar{q}_{k}}{\gamma^{2} \sigma_{z}^{2}}\right) \\
& \lambda_{d k}=\bar{\sigma}_{k}^{2} \bar{q}_{k}\left(1+\frac{\bar{\phi}_{k} \bar{q}_{k}}{\gamma^{2} \sigma_{z}^{2}}\right)
\end{aligned}
$$

where

$$
\bar{q}_{k}=\sum_{j \in \mathcal{B}_{k}} \frac{W_{1 j}}{N_{k}} \frac{1}{\sigma_{\eta_{j k}}^{2}}
$$

is a weighted-average of the signal precisions of the different agents, and $N_{k}=\left|\mathcal{B}_{k}\right|$ is cardinality of $\mathcal{B}_{k}$ - i.e. the number of countries whose agents choose to learn about asset $k$.

Thus, we have confirmed that the equilibrium price is linear and solved for its equilibrium coefficients.

\section{A.2 Information Choice}

In period 0 agents solve for the optimal information strategy, given their knowledge of optimal portfolios as a function of information (the solution to period 1 problem discussed above). First, we compute the time 1 expected utility conditional on an information choice. Using the optimal portfolio shares computed before, and evaluating the expected utility, conditional 
on the agent's full information set gives

$$
E_{1 j}\left[\frac{W_{1 j}^{1-\gamma}}{1-\gamma} \exp \left((1-\gamma) r_{j}^{p}\right)\right]=\frac{W_{1 j}^{1-\gamma}}{1-\gamma} \exp \left((1-\gamma) r^{f}+\frac{1-\gamma}{2 \gamma} \hat{\mu}_{j}^{\prime} \hat{\Sigma}_{j}^{-1} \hat{\mu}_{j}\right)
$$

where $\hat{\mu}_{j}=E_{1 j}(\mathbf{r})-r^{f}+\frac{1}{2} \operatorname{diag}\left(\hat{\Sigma}_{j}\right)$. Conditional on just the priors of agents in country $j$ (i.e. ex-ante), this is a Normal random variable, with the distribution $\hat{\mu}_{j} \sim N\left(\mathbf{m}_{j}, \Sigma-\hat{\Sigma}_{j}\right)$ where $\mathbf{m}_{j}$ is a $\mathrm{Nx} 1$ vectors with the following elements:

$$
m_{k}=\bar{\sigma}_{k}^{2}\left(\gamma \mu_{z k}-\frac{1}{2} \bar{\phi}_{k}\right)+\frac{1}{2} \hat{\sigma}_{j k}^{2}
$$

Thus, ex-ante excess return is increasing in the effective supply of the asset $\mu_{z k}$ and decreasing in the average invested wealth $\bar{\phi}_{k}$. Moreover, the variance of $\hat{\mu}_{j}$ is a diagonal matrix with the following diagonal elements

$$
\left(\Sigma-\widehat{\Sigma}_{j}\right)_{k k}=\underbrace{\bar{\sigma}_{k}^{2}\left(\bar{\phi}_{k}+\left(\gamma^{2} \sigma_{z}^{2}+\bar{\phi}_{k} \bar{q}_{k}\right) \bar{\sigma}_{k}^{2}\right)}_{=\sigma_{k}^{2}}-\hat{\sigma}_{j k}^{2}
$$

To get better intuition, note that $\sigma_{k}^{2}=\operatorname{Var}\left(d_{k}-p_{k}\right)$; thus $\sigma_{k}^{2}$ is the unconditional volatility of the excess return. Lastly, the above expected utility (17) was conditional on a choice of $\hat{\Sigma}_{j}$ and particular realizations of the informative signals. To compute the optimal information choice, we need to take its ex-ante expectation (meaning expectation over the actual realizations of signals and resulting asset prices). Doing so gives us

$$
\begin{aligned}
E_{0 j}\left[\frac{W_{1 j}^{1-\gamma}}{1-\gamma} \exp \left((1-\gamma) r_{j}^{p}\right)\right] & =\frac{W_{1 j}^{1-\gamma}}{1-\gamma} E_{0 j}\left[E_{1 j}\left[\exp \left((1-\gamma) r_{j}^{p}\right)\right]\right] \\
& \left.=\frac{W_{1 j}^{1-\gamma}}{1-\gamma} \exp \left((1-\gamma) r^{f}\right)\right) E_{0}\left[\exp \left(\frac{1-\gamma}{2 \gamma} \hat{\mu}_{j}^{\prime} \hat{\Sigma}_{j}^{-1} \hat{\mu}_{j}\right)\right] \\
& \left.=\frac{W_{1 j}^{1-\gamma}}{1-\gamma} \exp \left((1-\gamma) r^{f}\right)\right)\left|\frac{1}{\gamma} I-\frac{1-\gamma}{\gamma} \Sigma \hat{\Sigma}_{j}^{-1}\right|^{-\frac{1}{2}} * \\
& \exp \left(\frac{1-\gamma}{2 \gamma}\left[(1-\gamma) \mathbf{m}^{\prime} \hat{\Sigma}_{j}^{-1}\left(I-(1-\gamma) \Sigma \hat{\Sigma}_{j}^{-1}\right)^{-1}\left(\Sigma \hat{\Sigma}_{j}^{-1}-I\right)+I\right] \mathbf{m}\right)
\end{aligned}
$$

where we have applied the formula for the expectation of a Wishart variable to get from the second-to-last, to the last line. And finally, given the assumption that all variance matrices 
are diagonal, the log-objective function is

$$
\begin{aligned}
U_{0 j} & =-\ln \left(-\frac{W_{1 j}^{1-\gamma}}{1-\gamma} E_{0}\left[\exp \left((1-\gamma) r_{j}^{p}\right)\right]\right) \\
& =(1-\gamma) \ln \left(\frac{W_{1 j}}{\gamma-1}\right)+\sum_{k \in \mathcal{F}_{j}} \frac{1}{2} \ln \left(1+(\gamma-1) \frac{\sigma_{k}^{2}}{\hat{\sigma}_{j k}^{2}}\right)+\frac{\gamma-1}{2} \sum_{k \in \mathcal{F}_{j}} \frac{m_{k}^{2}}{\hat{\sigma}_{j k}^{2}+(\gamma-1) \sigma_{k}^{2}}+A
\end{aligned}
$$

where we perform the transformation $-\ln (-U)$ to avoid taking the logarithm of a negative number (recall we assume $\gamma>1$ ), and $A$ is a constant that does not depend on the posterior variances.

For notational convenience, for the rest of the analysis of an individual agent's problem, we will drop the $j$ subscript since the problems of agents in different countries are symmetric. Given that the risky factors are all Gaussian, the information content of the private signal about the asset return of country $k$ (in terms of entropy units) is $\kappa_{k}=\frac{1}{2}\left(\ln \left(\operatorname{Var}\left(d_{k} \mid p_{k}\right)-\ln \left(\operatorname{Var}\left(d_{k} \mid \mathcal{I}_{j}^{(i)}\right)\right.\right.\right.$. This follows from the expression for the entropy of Gaussian variables, and the fact that the only relevant public signal is the equilibrium market price $p_{k}$. Defining the variance of the risky payoffs conditional on public information only as $\tilde{\sigma}_{k}^{2}=\operatorname{Var}\left(d_{k}-p_{k} \mid p_{k}\right)$, and the conditional variance using all information as $\hat{\sigma}_{k}^{2}$, we have that $\hat{\sigma}_{k}^{2}=\exp \left(-\kappa_{k}\right) \tilde{\sigma}_{k}^{2}$; this shows us that the conditional variance of the agent is decreasing in the amount of information, $\kappa_{k}$, that he acquires.

We solve the information choice problem in three steps - a choice of allocation of intensive information, a choice of the total amount of intensive information acquired, and a choice of extensive information. First, note that given choices of the extensive information $\mathcal{F}$ and total intensive information $K$, agents solve the problem

$$
\max _{\kappa_{k}} \sum_{k \in \mathcal{F}} \frac{1}{2} \ln \left(1+(\gamma-1) \frac{\sigma_{k}^{2}}{\exp \left(-\kappa_{k}\right) \tilde{\sigma}_{k}^{2}}\right)+\frac{\gamma-1}{2} \sum_{k \in \mathcal{F}} \frac{m_{k}^{2}}{\exp \left(-\kappa_{k}\right) \tilde{\sigma}_{k}^{2}+(\gamma-1) \sigma_{k}^{2}}
$$


s.t.

$$
\sum_{k \in \mathcal{F}} \kappa_{k} \leq K
$$

\section{A.2.1 Step 1: Choice of $\kappa_{k}$}

The partial derivative of the objective function, $\frac{\partial U_{0}}{\partial \kappa_{k}}$, is

$$
\frac{(\gamma-1)\left[4 \hat{\sigma}_{k}^{2}\left(m_{k}^{2}+\sigma_{k}^{2}-(\gamma-1) m_{k} \sigma_{k}^{2}\right)+4(\gamma-1) \sigma_{k}^{4}-\hat{\sigma}_{k}^{6}-2(\gamma-1) \sigma_{k}^{2} \hat{\sigma}_{k}^{4}\right]}{8\left(\hat{\sigma}_{k}^{2}+(\gamma-1) \sigma_{k}^{2}\right)^{2}}
$$

and the second derivative, $\frac{\partial^{2} U_{0}}{\left(\partial \kappa_{k}\right)^{2}}$, is

$\frac{(\gamma-1)\left[\hat{\sigma}_{k}^{6}+3(\gamma-1) \hat{\sigma}_{k}^{4} \sigma_{k}^{2}+4(\gamma-1) \sigma_{k}^{2}\left(\sigma_{k}^{2}+(\gamma-1) m_{k} \sigma_{k}^{2}-m_{k}^{2}\right)+4 \hat{\sigma}_{k}^{2}\left(m_{k}^{2}+\sigma_{k}^{2}\left(1+(\gamma-1)^{2} \sigma_{k}^{2}\right)-(\gamma-1) m_{k}\right)\right]}{8\left(\hat{\sigma}_{k}^{2}+(\gamma-1) \sigma_{k}^{2}\right)^{3}}$

A sufficient condition for $\frac{\partial^{2} U_{0}}{\left(\partial \kappa_{k}\right)^{2}}>0$ is that the unconditional Sharpe Ratio (SR) is less than $1\left(\frac{\bar{m}}{\sigma_{k}}<0\right)$, which is true in the data. Thus, assuming the SR is less than one implies that information choice is a convex problem. Moreover, if $4>\gamma \tilde{\sigma}_{k}^{2}$, which is also true under realistic parameters, we can show that the partial derivative with respect to information about asset $k$ is positive when the agent's posterior variance equals the unconditional variance of the asset $k$ :

$$
\left.\frac{\partial U_{0}}{\partial \kappa_{k}}\right|_{\hat{\sigma}_{k}^{2}=\sigma_{k}^{2}}>0
$$

Together with the fact that the second derivative is also positive, we can conclude that the partial derivative in respect to information is always positive and increasing. Thus, the optimal information allocation is such that $\kappa_{j *}=K$ for one specific $k$, and $\kappa_{k}=0$ for all $k \neq j *$. 


\section{A.2.2 Step 2: Choice of $K$}

Choosing $K$ amounts to choosing the amount of total additional information to acquire about the optimal asset $j^{*}$. The problem (18) becomes

$$
\begin{aligned}
& \max _{K}(\gamma-1) \ln \left(W_{1}\right)+\frac{1}{2} \ln \left(\frac{\exp (-K) \tilde{\sigma}_{j *}^{2}+(\gamma-1) \sigma_{j *}^{2}}{\exp (-K) \tilde{\sigma}_{j *}^{2}}\right)+\frac{\gamma-1}{2} \frac{m_{j *}^{2}}{\exp (-K) \tilde{\sigma}_{j *}^{2}+(\gamma-1) \sigma_{j *}^{2}}+ \\
& \quad+\sum_{k \in \mathcal{F}} \frac{1}{2} \ln \left(\frac{\tilde{\sigma}_{k}^{2}+(\gamma-1) \sigma_{k}^{2}}{\tilde{\sigma}_{k}^{2}}\right)+\frac{\gamma-1}{2} \sum_{k \in \mathcal{F}} \frac{m_{k}^{2}}{\tilde{\sigma}_{k}^{2}+(\gamma-1) \sigma_{k}^{2}}
\end{aligned}
$$

The first order condition of this problem is

$$
\frac{C^{\prime}\left(K^{*}\right)}{W_{1}}=\frac{(\gamma-1)\left[4 \hat{\sigma}_{j *}^{2}\left(m_{j *}^{2}+\sigma_{j *}^{2}-(\gamma-1) m_{j *} \sigma_{j *}^{2}\right)+4(\gamma-1) \sigma_{j *}^{4}-\hat{\sigma}_{j *}^{6}-2(\gamma-1) \sigma_{j *}^{2} \hat{\sigma}_{j *}^{4}\right]}{8\left(\hat{\sigma}_{j *}^{2}+(\gamma-1) \sigma_{j *}^{2}\right)^{2}} .
$$

where $\hat{\sigma}_{j *}^{2}=\tilde{\sigma}_{j *}^{2} \exp \left(-K^{*}\right)$ and $\hat{\sigma}_{k}^{2}=\tilde{\sigma}_{j}^{2}$, for all $k \neq j *$. Given a convex information cost function $C($.$) , this defines a unique solution for total intensive information K^{*}$.

\section{A.2.3 Step 3: Choice of the set $\mathcal{F}$}

Lastly, we need to find the cutoff point at which adding new assets is not worth it anymore. The cost of adding an asset is that the investable wealth $W_{1}$ goes down by $c$. The gain for acquiring priors on asset $k$ and adding it to your portfolio is given by the term

$$
\ln \left(1+(\gamma-1) \frac{\sigma_{k}^{2}}{\tilde{\sigma}_{k}^{2}}\right)+\frac{\gamma-1}{2} \frac{\sigma_{k}^{2}\left(1+m_{k}^{2}\right)}{\tilde{\sigma}_{k}^{2}+(\gamma-1) \sigma_{k}^{2}}
$$

The first term captures the expected benefit of holding an additional asset with positive expected returns, and the second captures the diversification benefit of adding a new, independent asset to the portfolio. To arrive at that take the agent's ex-ante beliefs that $m_{k} \sim N\left(m_{k}, \sigma_{k}^{2}\right)$ and take expectations over the terms specific to asset $k$ in $U_{0}$.

The marginal cost of purchasing priors is increasing in the amount of assets you already 
learn about. This works through two different effects. First, note that

$$
\frac{\partial^{2} \ln \left(W_{1}\right)}{(\partial \Psi)^{2}}=-\frac{1}{W_{1}^{2}}
$$

which comes from the fact that marginal utility of investable wealth is declining, and further prior information acquisition, and thus incurring an additional fixed cost $c$, is becoming increasingly costlier in utility terms. Second, increases in $\Psi$ leads to lower investable wealth, and hence a lower optimal intensive information choice $K^{*}$ and therefore lower utility from trading the asset you purchase additional information about. Both of those effects combine to lead to the conclusion that there are increasing costs to increasing the breadth of information, and hence the portfolio. As a result, unless the fixed cost of acquiring priors is very small relative to the agent's wealth, it is unlikely that the bank will learn about all available assets. This generates sparse portfolios, with the level of sparseness varying with the agent's wealth.

\section{B Proofs}

\section{B.1 Proof of Proposition 1}

By the arguments in section A.2.1, the learning problem is convex and increasing in the precision of posterior beliefs. Since the home agents have a free signal on the home asset and both home and foreign agents observe the same public information, it is the case that

$$
\frac{\partial U_{0 j}}{\partial \kappa_{j}}>\frac{\partial U_{0 j^{\prime}}}{\partial \kappa_{j}},
$$

meaning that the marginal utility of information about the home asset (asset $j$ for agents in country $j$ ) is always higher than the marginal utility of the same information to a foreign agent (agent in $j^{\prime} \neq j$ ). As a result, if any agent in country $j^{\prime} \neq j$ finds it optimal to specialize in asset $j$, it must be the case that all agents in country $j$ already specialize in their home asset as well. Essentially, agents have a comparative advantage to learning about their home 
asset. Thus if $k_{j^{\prime} j}>0$, then

$$
\kappa_{j j}=\kappa_{j^{\prime} j}
$$

and both agents specialize in the asset $j$. If a foreign agent does not acquire information about asset $j$, then it is either the case that the country $j$ agents specialize in their home asset anyway and thus

$$
\kappa_{j j}>\kappa_{j^{\prime} j}=0
$$

or the country $j$ agents specialize in some other asset as well, and thus

$$
\kappa_{j j}=\kappa_{j^{\prime} j}=0
$$

As a result, we see that it is always the case that

$$
\kappa_{j j} \geq \kappa_{j^{\prime} j}
$$

In the special case of a symmetric world, since we know that the agents have a comparative advantage over home assets and all world assets are ex-ante identical, it follows that everyone specializes in their home asset. As a result

$$
\kappa_{j j}>\kappa_{j^{\prime} j}=0 .
$$

\section{B.2 Proof of Proposition 2}

1. In a symmetric world where all fundamental terms have the same variance $\sigma_{k}^{2}=\sigma^{2}$ for all $k$ and the ex-ante expected return on all assets is the same, $m_{k}=m$ for all $k$, all asset prices are symmetric in the sense that they are the same linear function of their respective state variables. Thus, all price coefficients are the same, $\lambda_{d k}=\lambda_{d}, \lambda_{z k}=\lambda_{z}$, and $\bar{\lambda}_{k}=\bar{\lambda}$ for all $k$, and the price only differ from each other because of different 
realizations of the state variables:

$$
p_{k}=\bar{\lambda}+\lambda_{d} d_{k}+\lambda_{z} z_{k}
$$

As a result, the precision of information that can be acquired from the price signal, $\frac{\lambda_{d}^{2}}{\lambda_{z}^{2} \sigma_{z}^{2}}$ is the same for all prices. Combined with the fact that all fundamentals have the same prior variance, this implies that the variance conditional on public information is also the same for all assets:

$$
\tilde{\sigma}_{k}^{2}=\tilde{\sigma}^{2}
$$

for all $k$. Thus, in this symmetric world assets are symmetric not only ex-ante, but also conditional on all publicly available information.

Then, turning to the information choice of agents, note that the gain (in utility terms) of doing a due diligence study and adding any new asset to your portfolio is:

$$
\ln \left(1+(\gamma-1) \frac{\sigma^{2}}{\tilde{\sigma}^{2}}\right)+\frac{\gamma-1}{2} \frac{\left.\sigma^{2}(1)+m^{2}\right)}{\tilde{\sigma}^{2}+(\gamma-1) \sigma^{2}}
$$

which is again the same for all $k$, except for the home asset, in which case it is higher because of the extra free information signal.

The financial cost of doing the due diligence study is simply $c$, and in terms of utility it is given by (i) the decrease in log financial wealth (the first term of the objective function in equation (18)) and (ii) the associated decrease in the optimal $K^{*}$. The marginal utility cost of spending an extra $c$, when you have already spent the amount $\Psi=\sum_{k \in \mathcal{F}} c$ on prior information and have chosen the resulting optimal intensive information $K^{*}(|\mathcal{H}|)$ is: :

$\ln \left(W-C\left(K^{*}(|\mathcal{F}|)\right)-\Psi\right)-\ln \left(W-C\left(K^{*}(|\mathcal{F}|+1)\right)-\Psi-c\right)=\ln \left(\frac{W-C\left(K^{*}(|\mathcal{F}|)\right)-\Psi}{W-C\left(K^{*}(|\mathcal{F}|+1)\right)-\Psi-c}\right)$ 
Since the log function is concave, this utility cost is increasing in the total amount of resources spent on due diligence studies.

Thus, we can conclude that if

$$
\ln \left(\frac{W-C\left(K^{*}(0)\right)}{W-C\left(K^{*}(1)\right)-c}\right)<\ln \left(1+(\gamma-1) \frac{\sigma^{2}}{\tilde{\sigma}^{2}}\right)+\frac{\gamma-1}{2} \frac{\sigma^{2}+m^{2}}{\tilde{\sigma}^{2}+(\gamma-1) \sigma^{2}}
$$

then the gain from adding the first foreign asset to their learning portfolio exceeds the cost of doing so, hence the agents will invest in at least one foreign asset. However, since the log function is concave, the utility cost of due diligence studies is increasing in the total amount of due diligence studies already done. So as long as the initial wealth of an agent $W$ is low enough so that

$$
\ln \left(\frac{W-C\left(K^{*}(N-1)\right)-(N-1) c}{W-C\left(K^{*}(N)\right)-N c}\right)>\ln \left(1+(\gamma-1) \frac{\sigma^{2}}{\tilde{\sigma}^{2}}\right)+\frac{\gamma-1}{2} \frac{\sigma^{2}+m^{2}}{\tilde{\sigma}^{2}+(\gamma-1) \sigma^{2}}
$$

then the agents will not invest in all foreign assets and hence

$$
\alpha_{k}=0 \text { for some } k
$$

2. For the same reason that the log financial wealth function is concave, it follows that increasing $W$ lowers the cost of doing an additional due diligence study i.e.:

$$
\frac{\partial \ln \left(\frac{W-C\left(K^{*}(|\mathcal{H}|)\right)-\Psi}{W-C\left(K^{*}(|\mathcal{H}|+1)\right)-\Psi-c}\right)}{\partial W}<0
$$

Thus, as $W$ increases the agents will add new assets to their learning portfolio, and hence the sparseness of portfolios will decrease.

3. Because the agent optimally chooses to not acquire any extra intensive information about his foreign portfolio holdings, the optimal portfolio holdings of these assets depend on the 
public information contained in prices and priors. Evaluating the associated conditional expectation, and plugging in the solution for the equilibrium price coefficients, we can show that the equilibrium holdings of a foreign asset $k$ is given by

$$
\alpha_{k}=\left(\tilde{\sigma}_{k}^{2}-\bar{\sigma}_{k}^{2} \phi_{k}\right)\left(\frac{\mu_{d k}}{\sigma_{k}^{2}}+\frac{q_{k}}{\gamma \sigma_{z k}^{2}}\right)+\gamma \bar{\sigma}_{k}^{2} z_{k}+\frac{\bar{\sigma}_{k}^{2} \phi_{k}-\tilde{\sigma}_{k}^{2}}{\gamma \tilde{\sigma}_{k}^{2}}\left(\frac{d_{k}}{\sigma_{k}^{2}}+\frac{q_{k}}{\gamma \sigma_{z k}^{2}} z_{k}\right)
$$

The first term is a constant, which is the same for all foreign holdings in a symmetric world (since all $\mathrm{k}$ subscripts fall out). Thus, the equilibrium holdings of foreign assets only differ from one another due to the specific realizations of the noise trading term $z_{k}$ and payoff $d_{k}$.

Since those have asymmetric distributions across $k$, however, it follows that the average holdings of two foreign assets $k$ and $k^{\prime}$ are the same

$$
E\left(\alpha_{k}\right)=E\left(\alpha_{k^{\prime}}\right)
$$

Thus, at the steady state all foreign holdings are equal to each other, hence as a share of the foreign portion of the portfolio they are all equal to $\frac{1}{\tilde{N}}$ where $\tilde{N}=|\mathcal{F}|-1$ is the number of foreign countries the agents actually invest in. In a symmetric world all assets are in the same supply $\bar{z}$, hence,$\frac{1}{\tilde{N}}$ is also the market share of each of the foreign assets within the sub-portfolio of assets that agent $j$ invests in.

Thus, up to a first order approximation the average value of the Bias $_{k}$ index (for an agent in country $j$ ) is:

$$
E\left(\text { Bias }_{k}\right)=1-E\left(\frac{1-\frac{\alpha_{k}}{\sum_{k^{\prime} \in \mathcal{F} / \mid} \alpha_{k^{\prime}}}}{1-\frac{1}{\tilde{N}}}\right) \approx 1-\frac{1-\frac{1}{\tilde{N}}}{1-\frac{1}{\tilde{N}}}=0
$$




\section{Portfolio Comparative Statics: PE vs GE}

Although the comparative statics exercises in Proposition 2 are only partial equilibrium expressions, they are still useful to gain intuition and the results carry over to general equilibrium as well. In general equilibrium, if everyone revises their expectations about asset $k$ upwards, it clearly cannot be the case that everyone also increases their holdings of asset $k$. The price will adjust to this increase in demand, and in fact only the agents who increased their beliefs more than the average belief are the ones who will increase their portfolios. Substituting in the expression for the equilibrium price, $p_{k}$, in the optimal holdings expression, we can show that the equilibrium portfolio holdings of asset $k$ of bank $j$ are given by

$$
\alpha_{j k}=\frac{\left.E_{1 j}\left(d_{k}\right)\right)-\bar{E}_{1}\left(d_{k}\right)}{\gamma \hat{\sigma}_{j k}^{2}}+\frac{1}{2 \gamma}\left(1-\frac{\bar{\sigma}_{k}^{2}}{\hat{\sigma}_{j k}^{2}} \bar{\phi}_{k}\right)+\gamma z_{k} \frac{\bar{\sigma}_{k}^{2}}{\hat{\sigma}_{j k}^{2}}
$$

where we define the average market expectation (wealth-weighted) $\bar{E}_{1}\left(d_{k}\right)$ as

$$
\bar{E}_{1}\left(d_{k}\right)=\bar{\sigma}_{k}^{2}\left(\sum_{j \in \mathcal{B}_{k}} \frac{W_{1 j}}{N_{k}} \frac{\int E_{1 j}^{(i)}\left(d_{k}\right) d i}{\hat{\sigma}_{j k}^{2}}\right)
$$

As we can see, the basic results of the partial equilibrium comparative statics still remain true as long as you control for the average market beliefs. Agents will hold more of a given asset the more optimistic they are about its return relative to the average market belief, the higher the precision of their beliefs relative to the average market precision, and their portfolio holdings will be more responsive to their relative optimism, the greater is the precision of their beliefs. In our empirical tests we control for all of this market effects by including the appropriate fixed effects. 


\section{Additional Tables}

Table 9: Number of forecasters per country

This table contains the number of forecasters for each country in Consensus Economics. Observations refers to the number of forecasters $\times$ number of months in the sample.

\begin{tabular}{lcccccc} 
Country & Obs. & $\min$ & $\mathrm{p} 25$ & $\mathrm{p} 50$ & $\mathrm{p} 75$ & $\max$ \\
\hline France & 1645 & 2 & 14 & 15 & 16 & 18 \\
Germany & 2396 & 9 & 24 & 25 & 27 & 30 \\
Hungary & 1408 & 4 & 7 & 8 & 10 & 13 \\
Italy & 1201 & 2 & 7 & 8 & 9 & 13 \\
Japan & 1742 & 12 & 16 & 18 & 19 & 22 \\
Netherlands & 784 & 4 & 7 & 7 & 8 & 9 \\
Norway & 744 & 2 & 5 & 6 & 7 & 9 \\
Poland & 1454 & 5 & 9 & 10 & 11 & 13 \\
Slovakia & 989 & 0 & 5 & 6 & 7 & 9 \\
Spain & 1328 & 3 & 10 & 12 & 13 & 16 \\
Sweden & 1215 & 4 & 10 & 12 & 13 & 15 \\
Switzerland & 1278 & 8 & 11 & 12 & 12 & 14 \\
UK & 2015 & 4 & 16 & 17 & 19 & 23 \\
USA & 2313 & 16 & 23 & 25 & 27 & 32 \\
Total & 16184 & 5 & 10 & 12 & 13 & 15 \\
\hline \hline
\end{tabular}


Table 10: Forecasters

\begin{tabular}{|c|c|c|c|}
\hline ABI & DIW - Berlin & ISAE & OFCE \\
\hline ABN AMRO & DIW Berlin & ITEM Club & OTP Bank \\
\hline AFI & DNB & ITOCHU Institute & Oddo Securities \\
\hline AXA Investment Managers & DTZ Research & IW - Cologne Institute & Oxford - LBS \\
\hline Action Economics & DZ Bank & IfW - Kiel Institute & Oxford Economics \\
\hline Allianz & Daiwa Institute of Research & Inforum - Univ of Maryland & PAIR Conseil \\
\hline American Int'l Group & Danske Bank & Inst Estud Economicos & PKO Bank \\
\hline BAK Basel & DekaBank & Inst L R Klein (Gauss) & PNC Financial Services \\
\hline BBVA & Deutsche Bank & Institut Crea & Pictet \& Cie \\
\hline BHF-Bank & Dresdner Bank & Institute EIPF & Prometeia \\
\hline BIPE & DuPont & Instituto de Credito Oficial & RBS \\
\hline BNP Paribas & EFG Eurobank & Intesa Sanpaolo & RDQ Economics \\
\hline $\mathrm{BPCE}$ & ENI & JP Morgan & REF Ricerche \\
\hline $\mathrm{BPH}$ & Eaton Corporation & Japan Ctr for Econ Research & RWI Essen \\
\hline Banca Com Romana & Econ Institute SAV & Japan Tech Info Services Corp & Rabobank \\
\hline Banca IMI & Econ Intelligence Unit & KOF Swiss Econ Inst & Raiffeisen \\
\hline Banesto & Econ Policy Institute & KUKE & Rexecode \\
\hline Bank America Corp & Economic Perspectives & Kempen \& Co. & Roubini Global Econ \\
\hline Bank Julius Baer & Erik Penser Bank & Kiel Economics & SBAB Bank \\
\hline Bank Vontobel & Erste Bank & Kopint-Tarki & SEB \\
\hline Bank Zachodni & Est Inst of Econ Rsrch & La Caixa & Sal Oppenheim \\
\hline Bank of America & Euler Hermes & Landesbank Berlin & Santander \\
\hline Bank of Tokyo-Mits. UFJ & Euromonitor & Lehman Brothers & Schroders \\
\hline Bankia & Exane & Liverpool Macro Research & Skandiabanken \\
\hline Barclays & Experian & Lloyds TSB Financial Markets & Slovenska Sporitelna \\
\hline BayernLB & FERI & Lodz Institute - LIFEA & Societe Generale \\
\hline Beacon Econ Forecasting & FUNCAS & Lombard Street Research & Standard \& Poor's \\
\hline Bear Stearns & Fannie Mae & MESA 10 & Statistics Norway \\
\hline CASE & Feri EuroRating & MM Warburg & Svenska Handelsbanken \\
\hline CEOE & First Securities & Macroeconomic Advisers & Swedbank \\
\hline CEPREDE & First Trust Advisors & Merrill Lynch & Swiss Life \\
\hline CIB Budapest & Fitch Ratings & Millennium Bank & Swiss Re \\
\hline CSOB & Ford Motor Company & Mitsubishi Research Institute & Takarek Bank \\
\hline Caja Madrid & Fortis & Mitsubishi UFJ Research & Tatra Banka \\
\hline Cambridge Econometrics & GAMA & Mizuho Research Institute & The Conference Board \\
\hline Capital Economics & GKI Econ Research & Mizuho Securities & Theodoor Gilissen \\
\hline Capitalia & Gdansk University & Moody's Analytics & Total \\
\hline Centre Prev l'Expansion & General Motors & Morgan Stanley & Toyota Motor Corporation \\
\hline Centro Europa Ricerche & Georgia State University & NHO Conf Nor Enterprise & UBS \\
\hline Chamber of Commerce & Global Insight & NHO Confed Nor Enterprise & UniCredit \\
\hline Chrysler & Goldman Sachs & NIBC & United Bulgarian Bank \\
\hline Citigroup & HBOS & NIESR & United States Trust \\
\hline Coe-Rexecode & HQ Bank & NLI Research Institute & Univ of Michigan - RSQE \\
\hline Commerzbank & HSBC & NYKredit & Vienna Institute - WIIW \\
\hline Concorde Securities & HSH Nordbank & Nat Assn of Home Builders & WGZ Bank \\
\hline Confed of British Industry & HWWI & National Institute - NIER & Wachovia Corp \\
\hline Confed of Swed Enterprise & Helaba Frankfurt & Natixis & Wells Capital \\
\hline Confindustria & Hypo Alpe Adria & Nippon Steel & Wells Fargo \\
\hline Credit Agricole & IFL-Univers Carlos III & Nomura & WestLB \\
\hline Credit Suisse & IFO - Munich Institute & Nordea & Zircher Kantonalbank \\
\hline D\&B & ING & Northern Trust & Öhman \\
\hline Type & $\%$ & Type & $\%$ \\
\hline Bank & 51.50 & University & 2.88 \\
\hline Consulting Firm & 21.15 & Business Association & 2.59 \\
\hline Research Institute & 11.25 & Corporation & 2.02 \\
\hline Financial Services & 8.32 & Total & 100 \\
\hline
\end{tabular}


Table 11: Robustness Intensive Margin: Total Debt (incl. short-term debt)

This table provides a robustness test of the estimates for equation (14). The dependent variable is the share of EEA country $c$ sovereign bonds in bank $b$ sovereign portfolio. $Y 10$ is the 3 -month ahead forecast made by bank b regarding the 10-year yield on country $c$ 's sovereign debt averaged over quarter $t$. $\overline{S F E}(Y 10)$ is bank b's average squared forecast error regarding $Y 10$ throughout the sample period. Home equals one for domestic holdings, zero otherwise. Standard errors are reported in parentheses and are White-robust. $* * *, * *, *$ indicate statistical significance at $1 \%, 5 \%$, and $10 \%$, respectively.

Panel A. Foreign Exposures

\begin{tabular}{|c|c|c|c|c|}
\hline & $(1)$ & $(2)$ & $\overline{(3)}$ & $(4)$ \\
\hline$\overline{S F E}(Y 10)$ & $\begin{array}{c}-34.03^{* * *} \\
(7.965)\end{array}$ & $\begin{array}{c}-34.16^{* * * *} \\
(8.310)\end{array}$ & $\begin{array}{c}-48.14^{* * *} \\
(6.122)\end{array}$ & $\begin{array}{c}-16.98^{* *} \\
(6.527)\end{array}$ \\
\hline Y10 & $\begin{array}{c}-5.255^{* * *} \\
(0.967)\end{array}$ & $\begin{array}{c}-5.497^{* * *} \\
(0.925)\end{array}$ & $\begin{array}{c}-5.207^{* * *} \\
(0.629)\end{array}$ & $\begin{array}{l}-1.948 \\
(1.924)\end{array}$ \\
\hline$\overline{S F E}(Y 10) \times Y 10$ & $\begin{array}{c}6.197^{* * *} \\
(1.288)\end{array}$ & $\begin{array}{c}6.336^{* * *} \\
(1.325)\end{array}$ & $\begin{array}{c}7.859^{* * *} \\
(0.916)\end{array}$ & $\begin{array}{c}3.393^{* * *} \\
(1.059)\end{array}$ \\
\hline Observations & 175 & 175 & 173 & 153 \\
\hline Adj. $R^{2}$ & 0.187 & 0.185 & 0.637 & 0.761 \\
\hline $\mathrm{N}$ of Banks & 15 & 15 & 15 & 14 \\
\hline $\mathrm{N}$ of Destination Countries & 11 & 11 & 11 & 8 \\
\hline \multicolumn{5}{|c|}{ Panel B. Foreign and Domestic Exposures } \\
\hline & $(1)$ & $(2)$ & $(3)$ & $(4)$ \\
\hline$\overline{S F E}(Y 10)$ & $\begin{array}{c}-29.02^{* * *} \\
(7.949)\end{array}$ & $\begin{array}{c}-29.46^{* * *} \\
(8.162)\end{array}$ & $\begin{array}{c}-31.40^{* * *} \\
(9.636)\end{array}$ & $\begin{array}{c}-40.83^{* * *} \\
(9.536)\end{array}$ \\
\hline Y10 & $\begin{array}{c}-4.862^{* * *} \\
(1.015)\end{array}$ & $\begin{array}{c}-5.420^{* * * *} \\
(0.966)\end{array}$ & $\begin{array}{c}-4.069^{* * *} \\
(0.862)\end{array}$ & $\begin{array}{l}-4.757 \\
(3.120)\end{array}$ \\
\hline$\overline{S F E}(Y 10) \times Y 10$ & $\begin{array}{c}5.486^{* * *} \\
(1.295)\end{array}$ & $\begin{array}{c}5.791^{* * *} \\
(1.312)\end{array}$ & $\begin{array}{c}5.399^{* * *} \\
(1.458)\end{array}$ & $\begin{array}{c}7.021^{* * *} \\
(1.715)\end{array}$ \\
\hline Home & $\begin{array}{c}26.28^{* * *} \\
(2.645)\end{array}$ & $\begin{array}{c}25.74^{* * *} \\
(2.645)\end{array}$ & $\begin{array}{c}24.15^{* * *} \\
(2.981)\end{array}$ & $\begin{array}{c}20.65^{* * *} \\
(2.256)\end{array}$ \\
\hline Observations & 254 & 254 & 254 & 236 \\
\hline Adj. $R^{2}$ & 0.512 & 0.507 & 0.689 & 0.750 \\
\hline $\mathrm{N}$ of Banks & 15 & 15 & 15 & 15 \\
\hline $\mathrm{N}$ of Destination Countries & 11 & 11 & 11 & 10 \\
\hline Time FE & no & yes & yes & - \\
\hline Bank FE & no & no & yes & yes \\
\hline Country-Time FE & no & no & no & yes \\
\hline
\end{tabular}


Table 12: Robustness Intensive Margin: 1-year ahead forecast of 10-year yields

This table provides a robustness test of the estimates for equation (14). The dependent variable is the share of EEA country $c$ sovereign bonds in bank $b$ sovereign portfolio of long-term debt ( $>5$ years residual maturity). $Y 10 \_2_{b, c, t}$ is the 1-year ahead forecast made by bank b regarding the 10-year yield on country $c$ 's sovereign debt averaged over quarter $t$. $\overline{S F E}\left(Y 10 \_2\right)$ is bank $b$ 's average squared forecast error regarding $Y 10 \_2$ throughout the sample period. Home equals one for domestic holdings, zero otherwise. Home equals one for domestic forecasts only. Standard errors are White robust. $* * *, * *, *$ indicate statistical significance at $1 \%$, $5 \%$, and $10 \%$, respectively.

\begin{tabular}{|c|c|c|c|c|}
\hline & (1) & $(2)$ & $(3)$ & $(4)$ \\
\hline$\overline{S F E}\left(Y 10 \_2\right)$ & $\begin{array}{c}-15.48^{* * *} \\
(3.101)\end{array}$ & $\begin{array}{c}-14.94^{* * *} \\
(3.120)\end{array}$ & $\begin{array}{c}-17.19^{* * *} \\
(2.976)\end{array}$ & $\begin{array}{c}-10.29^{*} \\
(5.344)\end{array}$ \\
\hline$Y 10 \_2$ & $\begin{array}{c}-5.650^{* * *} \\
(1.179)\end{array}$ & $\begin{array}{c}-5.845^{* * *} \\
(1.128)\end{array}$ & $\begin{array}{c}-4.851^{* * *} \\
(0.677)\end{array}$ & $\begin{array}{c}-6.485^{* * *} \\
(2.081)\end{array}$ \\
\hline$\overline{S F E}\left(Y 10 \_2\right) \times Y 10 \_2$ & $\begin{array}{c}2.616^{* * *} \\
(0.555)\end{array}$ & $\begin{array}{c}2.545^{* * *} \\
(0.556)\end{array}$ & $\begin{array}{c}2.828^{* * *} \\
(0.504)\end{array}$ & $\begin{array}{l}2.072^{* *} \\
(1.039)\end{array}$ \\
\hline Observations & 171 & 171 & 168 & 147 \\
\hline Adj. $R^{2}$ & 0.156 & 0.152 & 0.760 & 0.801 \\
\hline $\mathrm{N}$ of Banks & 14 & 14 & 14 & 13 \\
\hline $\mathrm{N}$ of Destination Countries & 11 & 11 & 11 & 8 \\
\hline \multicolumn{5}{|c|}{ Panel B. Foreign and Domestic Exposures } \\
\hline & $(1)$ & $(2)$ & $(3)$ & $(4)$ \\
\hline$\overline{S F E}\left(Y 10 \_2\right)$ & $\begin{array}{c}-11.82^{* * *} \\
(3.446)\end{array}$ & $\begin{array}{c}-11.44^{* * *} \\
(3.441)\end{array}$ & $\begin{array}{c}-10.28^{* *} \\
(4.906)\end{array}$ & $\begin{array}{c}-15.88^{* * *} \\
(5.941)\end{array}$ \\
\hline$Y 10 \_2$ & $\begin{array}{c}-4.767^{* * *} \\
(1.264)\end{array}$ & $\begin{array}{c}-5.163^{* * *} \\
(1.175)\end{array}$ & $\begin{array}{c}-3.201^{* * *} \\
(1.047)\end{array}$ & $\begin{array}{c}-0.800 \\
(2.896)\end{array}$ \\
\hline$\overline{S F E}\left(Y 10 \_2\right) \times Y 10 \_2$ & $\begin{array}{c}2.063^{* * *} \\
(0.609)\end{array}$ & $\begin{array}{c}2.047^{* * *} \\
(0.602)\end{array}$ & $\begin{array}{l}1.851^{* *} \\
(0.762)\end{array}$ & $\begin{array}{c}2.954^{* * *} \\
(1.098)\end{array}$ \\
\hline Home & $\begin{array}{c}32.17^{* * *} \\
(3.343)\end{array}$ & $\begin{array}{c}31.72^{* * *} \\
(3.370)\end{array}$ & $\begin{array}{c}30.68^{* * *} \\
(3.471)\end{array}$ & $\begin{array}{c}25.53^{* * *} \\
(2.328)\end{array}$ \\
\hline Observations & 240 & 240 & 240 & 222 \\
\hline Adj. $R^{2}$ & 0.499 & 0.488 & 0.735 & 0.786 \\
\hline $\mathrm{N}$ of Banks & 14 & 14 & 14 & 14 \\
\hline $\mathrm{N}$ of Destination Countries & 11 & 11 & 11 & 10 \\
\hline Time FE & no & yes & yes & - \\
\hline Bank FE & no & no & yes & yes \\
\hline Country-Time FE & no & no & no & yes \\
\hline
\end{tabular}


Table 13: Robustness Intensive Margin: No Peripheral (GIIPS) Debt exposure

This table provides a robustness test of the estimates for equation (14), excluding the holdings of sovereign debt issued by peripheral countries (Greece, Ireland, Italy, Portugal and Spain). The dependent variable is the share of EEA country $c$ sovereign bonds in bank $b$ sovereign portfolio of long-term debt ( $>5$ years residual maturity). $Y 10$ is the 3 -month ahead forecast made by bank b regarding the 10 -year yield on country $c$ 's sovereign debt averaged over quarter $t . \overline{S F E}(Y 10)$ is bank $b$ 's average squared forecast error regarding $Y 10$ throughout the sample period. Home equals one for domestic holdings, zero otherwise. Standard errors are reported in parentheses and are White-robust. ${ }^{* * *}, * *, *$ indicate statistical significance at $1 \%, 5 \%$, and $10 \%$, respectively.

Panel A. Foreign Exposures

\begin{tabular}{|c|c|c|c|c|}
\hline & $(1)$ & $(2)$ & $(3)$ & $(4)$ \\
\hline$\overline{S F E}(Y 10)$ & $\begin{array}{c}-38.31^{* * *} \\
(11.288)\end{array}$ & $\begin{array}{c}-38.38^{* * *} \\
(11.561)\end{array}$ & $\begin{array}{c}-42.36^{* * *} \\
(8.930)\end{array}$ & $\begin{array}{c}-30.22^{* * *} \\
(9.141)\end{array}$ \\
\hline Y10 & $\begin{array}{c}-5.526^{* * *} \\
(1.387)\end{array}$ & $\begin{array}{c}-5.918^{* * *} \\
(1.336)\end{array}$ & $\begin{array}{c}-3.662^{* * *} \\
(0.844)\end{array}$ & $\begin{array}{c}-4.810^{* *} \\
(2.101)\end{array}$ \\
\hline$\overline{S F E}(Y 10) \times Y 10$ & $\begin{array}{c}6.969^{* * *} \\
(1.954)\end{array}$ & $\begin{array}{c}7.125^{* * *} \\
(1.944)\end{array}$ & $\begin{array}{c}7.045^{* * *} \\
(1.491)\end{array}$ & $\begin{array}{c}7.242^{* * *} \\
(1.781)\end{array}$ \\
\hline Observations & 154 & 154 & 152 & 141 \\
\hline Adj. $R^{2}$ & 0.148 & 0.143 & 0.765 & 0.847 \\
\hline $\mathrm{N}$ of Banks & 15 & 15 & 15 & 14 \\
\hline $\mathrm{N}$ of Destination Countries & 9 & 9 & 9 & 7 \\
\hline \multicolumn{5}{|c|}{ Panel B. Foreign and Domestic Exposures } \\
\hline & $(1)$ & $(2)$ & $(3)$ & $(4)$ \\
\hline$\overline{S F E}(Y 10)$ & $\begin{array}{c}-56.42^{* * *} \\
(12.648)\end{array}$ & $\begin{array}{c}-57.06^{* * *} \\
(12.653)\end{array}$ & $\begin{array}{l}-27.89^{* *} \\
(12.684)\end{array}$ & $\begin{array}{r}-71.43^{* * *} \\
(12.379)\end{array}$ \\
\hline Y10 & $\begin{array}{c}-6.678^{* * *} \\
(1.460)\end{array}$ & $\begin{array}{c}-7.281^{* * * *} \\
(1.381)\end{array}$ & $\begin{array}{c}-2.572^{* *} \\
(1.121)\end{array}$ & $\begin{array}{c}-5.955^{*} \\
(3.271)\end{array}$ \\
\hline$\overline{S F E}(Y 10) \times Y 10$ & $\begin{array}{c}9.792^{* * *} \\
(2.111)\end{array}$ & $\begin{array}{c}10.11^{* * *} \\
(2.070)\end{array}$ & $\begin{array}{l}4.991^{* *} \\
(1.986)\end{array}$ & $\begin{array}{c}13.43^{* * *} \\
(2.130)\end{array}$ \\
\hline Home & $\begin{array}{c}29.54^{* * * *} \\
(3.405) \\
\end{array}$ & $\begin{array}{c}29.09^{* * *} \\
(3.414) \\
\end{array}$ & $\begin{array}{c}30.18^{* * *} \\
(3.553)\end{array}$ & $\begin{array}{c}22.49^{* * *} \\
(2.374)\end{array}$ \\
\hline Observations & 220 & 220 & 220 & 210 \\
\hline Adj. $R^{2}$ & 0.508 & 0.496 & 0.730 & 0.799 \\
\hline $\mathrm{N}$ of Banks & 14 & 14 & 14 & 14 \\
\hline $\mathrm{N}$ of Destination Countries & 9 & 9 & 9 & 9 \\
\hline Time FE & no & yes & yes & - \\
\hline Bank FE & no & no & yes & yes \\
\hline Country-Time FE & no & no & no & yes \\
\hline
\end{tabular}


Table 14: Robustness Intensive Margin: Lagged Information Set $(t-1)$ to calculate $\overline{S F E}_{b, c, t-1}$

This table provides a robustness test of the estimates for equation (14). The dependent variable is the share of EEA country $c$ sovereign bonds in bank $b$ sovereign portfolio of long-term debt ( $>5$ years residual maturity). $Y 10$ is the 3-month ahead forecast made by bank b regarding the 10-year yield on country c's sovereign debt averaged over quarter $t . \overline{S F E}(Y 10)_{t-1}$ is bank $b$ 's average squared forecast error regarding $Y 10$ calculated up to period $(t-1)$. Home equals one for domestic holdings, zero otherwise. Standard errors are reported in parentheses and are White-robust. ${ }^{* * *}, * *,{ }^{*}$ indicate statistical significance at $1 \%, 5 \%$, and $10 \%$, respectively.

Panel A. Foreign Exposures

\begin{tabular}{|c|c|c|c|c|}
\hline & $(1)$ & $(2)$ & 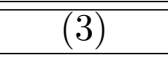 & $(\overline{(4)}$ \\
\hline$\overline{S F E}\left(Y 10 \_1\right)_{t-1}$ & $\begin{array}{c}-17.48^{* * *} \\
(6.277)\end{array}$ & $\begin{array}{c}-16.32^{* *} \\
(6.450)\end{array}$ & $\begin{array}{c}-16.52^{* * *} \\
(4.547)\end{array}$ & $\begin{array}{c}-11.59^{* * *} \\
(3.633)\end{array}$ \\
\hline Y10_1 & $\begin{array}{c}-4.159^{* * *} \\
(1.058)\end{array}$ & $\begin{array}{c}-4.338^{* * *} \\
(1.023)\end{array}$ & $\begin{array}{c}-2.958^{* * *} \\
(0.588)\end{array}$ & $\begin{array}{c}-2.393 \\
(1.700)\end{array}$ \\
\hline$\overline{S F E}\left(Y 10 \_1\right)_{t-1} \times Y 10 \_1$ & $\begin{array}{c}3.365^{* * *} \\
(1.105)\end{array}$ & $\begin{array}{c}3.264^{* * *} \\
(1.105)\end{array}$ & $\begin{array}{c}3.053^{* * *} \\
(0.800)\end{array}$ & $\begin{array}{c}3.780^{* * *} \\
(0.996)\end{array}$ \\
\hline Observations & 175 & 175 & 173 & 153 \\
\hline Adj. $R^{2}$ & 0.101 & 0.0903 & 0.704 & 0.789 \\
\hline $\mathrm{N}$ of Banks & 15 & 15 & 15 & 14 \\
\hline $\mathrm{N}$ of Destination Countries & 11 & 11 & 11 & 8 \\
\hline \multicolumn{5}{|c|}{ Panel B. Foreign and Domestic Exposures } \\
\hline & $(1)$ & $(2)$ & $(3)$ & $(4)$ \\
\hline$\overline{S F E}\left(Y 10 \_1\right)_{t-1}$ & $\begin{array}{c}-15.94^{* * *} \\
(5.954)\end{array}$ & $\begin{array}{c}-15.16^{* *} \\
(6.051)\end{array}$ & $\begin{array}{c}-14.67^{* *} \\
(5.930)\end{array}$ & $\begin{array}{c}-23.00^{* * *} \\
(7.084)\end{array}$ \\
\hline Y10_1 & $\begin{array}{c}-4.211^{* * *} \\
(1.089)\end{array}$ & $\begin{array}{c}-4.408^{* * *} \\
(1.038)\end{array}$ & $\begin{array}{c}-2.593^{* * *} \\
(0.772)\end{array}$ & $\begin{array}{l}-2.118 \\
(3.149)\end{array}$ \\
\hline$\overline{S F E}\left(Y 10 \_1\right)_{t-1} \times Y 10 \_1$ & $\begin{array}{c}3.215^{* * *} \\
(1.072)\end{array}$ & $\begin{array}{c}3.160^{* * *} \\
(1.059)\end{array}$ & $\begin{array}{c}2.820^{* * *} \\
(0.944)\end{array}$ & $\begin{array}{c}5.982^{* * *} \\
(1.399)\end{array}$ \\
\hline Home & $\begin{array}{c}32.48^{* * *} \\
(3.064)\end{array}$ & $\begin{array}{c}32.23^{* * *} \\
(3.084)\end{array}$ & $\begin{array}{c}30.85^{* * *} \\
(3.264)\end{array}$ & $\begin{array}{c}26.66^{* * *} \\
(2.352)\end{array}$ \\
\hline Observations & 254 & 254 & 254 & 236 \\
\hline Adj. $R^{2}$ & 0.526 & 0.515 & 0.743 & 0.788 \\
\hline $\mathrm{N}$ of Banks & 15 & 15 & 15 & 15 \\
\hline $\mathrm{N}$ of Destination Countries & 11 & 11 & 11 & 10 \\
\hline Time FE & no & yes & yes & - \\
\hline Bank FE & no & no & yes & yes \\
\hline Country-Time FE & no & no & no & yes \\
\hline
\end{tabular}


Table 15: Robustness Intensive Margin: Eurozone exposures only

This table provides a robustness test of the estimates for equation (14). . The dependent variable is the share of Eurozone country $c$ sovereign bonds in bank $b$ sovereign portfolio of long-term debt ( $>5$ years residual maturity). $Y 10$ is the 3-month ahead forecast made by bank b regarding the 10-year yield on country $c$ 's sovereign debt averaged over quarter $t . \overline{S F E}(Y 10)$ is bank $b$ 's average squared forecast error regarding $Y 10$ throughout the sample period. Home equals one for domestic holdings, zero otherwise.Standard errors are reported in parentheses and are White-robust. $* * *, * * *$ indicate statistical significance at $1 \%, 5 \%$, and $10 \%$, respectively.

Panel A. Foreign Exposures

\begin{tabular}{|c|c|c|c|c|}
\hline & $(1)$ & $(2)$ & $(3)$ & $(4)$ \\
\hline$\overline{S F E}(Y 10)$ & $\begin{array}{c}-59.77^{* * *} \\
(16.200)\end{array}$ & $\begin{array}{c}-56.85^{* * *} \\
(16.734)\end{array}$ & $\begin{array}{c}-64.80^{* * *} \\
(7.461)\end{array}$ & $\begin{array}{r}-53.97^{* * *} \\
(17.262)\end{array}$ \\
\hline Y10 & $\begin{array}{c}-11.87^{* * *} \\
(1.820)\end{array}$ & $\begin{array}{c}-12.78^{* * *} \\
(1.774)\end{array}$ & $\begin{array}{c}-9.164^{* * *} \\
(0.780)\end{array}$ & $\begin{array}{c}-5.937^{*} \\
(3.005)\end{array}$ \\
\hline$\overline{S F E}(Y 10) \times Y 10$ & $\begin{array}{c}9.570^{* * *} \\
(2.977)\end{array}$ & $\begin{array}{c}9.334^{* * *} \\
(3.037)\end{array}$ & $\begin{array}{c}10.23^{* * *} \\
(1.285)\end{array}$ & $\begin{array}{c}8.744^{* * *} \\
(2.709)\end{array}$ \\
\hline Observations & 97 & 97 & 91 & 78 \\
\hline Adj. $R^{2}$ & 0.340 & 0.307 & 0.912 & 0.942 \\
\hline $\mathrm{N}$ of Banks & 9 & 9 & 9 & 8 \\
\hline $\mathrm{N}$ of Destination Countries & 10 & 10 & 10 & 6 \\
\hline \multicolumn{5}{|c|}{ Panel B. Foreign and Domestic Exposures } \\
\hline & $(1)$ & $(2)$ & $(3)$ & $(4)$ \\
\hline$\overline{S F E}(Y 10)$ & $\begin{array}{c}-46.64^{* * *} \\
(15.245)\end{array}$ & $\begin{array}{c}-45.57^{* * *} \\
(15.759)\end{array}$ & $\begin{array}{c}-63.66^{* * *} \\
(19.402)\end{array}$ & $\begin{array}{c}-18.19 \\
(18.002)\end{array}$ \\
\hline Y10 & $\begin{array}{c}-10.08^{* * *} \\
(1.725)\end{array}$ & $\begin{array}{c}-10.89^{* * *} \\
(1.718)\end{array}$ & $\begin{array}{c}-8.185^{* * *} \\
(1.333)\end{array}$ & $\begin{array}{l}-5.945 \\
(4.411)\end{array}$ \\
\hline$\overline{S F E}(Y 10) \times Y 10$ & $\begin{array}{c}7.462^{* * *} \\
(2.749)\end{array}$ & $\begin{array}{c}7.502^{* * *} \\
(2.825)\end{array}$ & $\begin{array}{c}9.160^{* * *} \\
(3.343)\end{array}$ & $\begin{array}{c}3.556 \\
(3.162)\end{array}$ \\
\hline Home & $\begin{array}{c}5.755 \\
(4.609) \\
\end{array}$ & $\begin{array}{c}5.107 \\
(4.711) \\
\end{array}$ & $\begin{array}{c}14.79^{* * * *} \\
(4.740)\end{array}$ & $\begin{array}{c}17.78^{* * *} \\
(4.119) \\
\end{array}$ \\
\hline Observations & 120 & 120 & 120 & 105 \\
\hline Adj. $R^{2}$ & 0.339 & 0.312 & 0.749 & 0.835 \\
\hline $\mathrm{N}$ of Banks & 9 & 9 & 9 & 9 \\
\hline $\mathrm{N}$ of Destination Countries & 10 & 10 & 10 & 9 \\
\hline Time FE & no & yes & yes & - \\
\hline Bank FE & no & no & yes & yes \\
\hline Country-Time FE & no & no & no & yes \\
\hline
\end{tabular}

